\title{
In silico Investigation and Molecular Docking Study of Triazolo-thiadiazole Derivatives for Antimicrobial, Anti-inflammatory and Anti-diabetic Activity
}

\author{
Amol Sopanrao Dighe ${ }^{1,2, *}$, Ashim Kumar Sen ${ }^{1}$ \\ ${ }^{1}$ Department of Pharmacy, Sumandeep Vidyapeeth Deemed to be University, Piparia, Vadodara, Gujarat State, INDIA. \\ ${ }^{2}$ Department of Pharmaceutical Chemistry, Pravara Rural College of Pharmacy, Loni, Maharashtra, INDIA.
}

\begin{abstract}
Triazolo-thiadiazole and connected fused ring in heterocyclic compounds are of highly interest in potential bioactive molecules. Triazolo-thiadiazole derivatives have lead of organic chemists due to their good biological and chemotherapeutic significance. Research in the field of anti-mycobacterium, anti-inflammatory, anti-diabetic and antimicrobial therapies are ongoing and studies are seeking. Therefore, the discovery of new effective anti-mycobacterium, anti-inflammatory, anti-diabetic and antimicrobial agents are imperative. Swiss programs are used to predict Triazolo-thiadiazole derivatives properties that are important for drug profile. Later, all of them were docked into the active sites of enzymes namely Ribosomal RNA large subunit methyltransferase (1P91), PeriplasmicOligopeptide-Binding Protein (1B05) and Protein-tyrosine phosphatase, non-receptor type 1 (1q6s), those were considered in Antidiabetic studies of triazolothiazazole derivative. Docking study when compared with Triazolo-thiadiazole derivatives with standard drug, derivative docking result is better. Ciprofloxacin, ibuprofen, and acarbose have been used as standard drugs for antimicrobial, anti-inflammatory and antidiabetic activity in comparative docking studies.
\end{abstract}

Key words: Triazolo-thiodizole, Antibacterial, Anti-diabetic, Antitubercular, Anti-inflammatory.

\section{INTRODUCTION}

There has been much effort in the design and development of the novel triazolothiadiazole drugs from synthetic origin. ${ }^{1}$ Therefore, there is a growing interest in drugs potential. Triazolo-thiadiazole compounds are of more interest to biological activity. Triazolo-thiadiazole derivatives have lead of organic chemists due to their good biological and chemotherapeutic significance in many cases, the heterogeneous combination of the ring leads to extensive biological activity in the compounds. Some of the activities performed by asymmetrictripolo-thiadiazole include antibacterial, antiinflammatory, anti-diabetic and tubercular. The enzymes namely Ribosomal RNA large subunit methyltransferase (1P91), PeriplasmicOligopeptide-Binding Protein (1B05) and Protein-tyrosine phosphatase, non-receptor type 1 (1q6s), have been proposed as sensible targets for rational design of new Triazolo-thiadiazole derivatives with antidiabetic, antibacterial, anti-inflammatory activity. Process pharmacology is primarily concerned with the biological, analytical and biochemical aspects of the process, but the chemist must have productive interactions with those in other disciplines. The process of inventing new drugs is complex and involves the talents of people from different fields such as chemistry, biochemistry, molecular biology, physiology, pharmacy, and pharmacology. Molecular modeling software can detect drug properties such as physiochemical as well as drug size, shape, rational movement but accurately. Therefore, chemist holds a strategic position at the interface of chemistry and biology..$^{2-4}$
Submission Date: 04-03-2021; Revision Date: 18-05-2021; Accepted Date: 10-09-2021

DOI: 10.5530/ijper.55.4.213 Correspondence: Mr. Amol Sopanrao Dighe, Assistant Professor, Department

of Pharmaceutical Chemistry, Pravara Rural College of Pharmacy, Loni-413736, Maharashtra, INDIA. Phone: +91 9921642747, Email - amoldighe143@ gmail.com

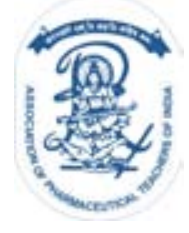

www.ijper.org 


\section{General procedure ${ }^{5-7}$}

Step -I General Procedure for Preparation of 2-amino-5-aryl-1, 3, 4-thiadizole

A mixture of thiosemicarbazide ( $0.1 \mathrm{~mole})$, aryl carboxylic acid (benzoic acid, 4-chloro benzoic acid) ( 0.1 mole) and hides. Sulfuric acid (10 drops) was refluxed for $45 \mathrm{~min}$. And was pour into crushed ice. The solidly separated with filter and washed with water and re-crystallized from spirit to give I.

Step -II General Procedure for Preparation of substituted 5-phenyl-N - [(1Z) -phenylmethylene] -1,3,4-thiadiazol-2-amine

Add $0.01 \mathrm{~mol}$ of 2-amino-5-aryl-1,3,4-thiadizole (I), a add of $18 \mathrm{ml}$ distilled water and $2.4 \mathrm{ml}$. of ammonium solution. Release $0.01 \mathrm{~mol}$ of NH3 and aldehyde (anisalaldehyde, salicylaseled) with stirring over a period of 30-45 min. Stir well the mixture for further few minutes, collect the solid mass by suction filtration and wash it with distilled water. Recalled from Rectified Spirit.

Step-III General Procedure for Triazolothiadizole (III) in preparation of 2, 5 .

A mixture of imine (II) 0.01 mole and $\mathrm{FeCl}_{3} \cdot 6 \mathrm{H}_{2} \mathrm{O}(0.02$ mole) and 0.01 mole of Isoniazide/ Pyrazinoic acid hydrides was ground at normal emperature by pestle and mortar. After complete conversion indicated by TLC. The reaction mixture was dissolve with cold water. The resulting crude solid mass was filtered, washed with distilled water and re-crystallizing with methanol.

Detection Method: The docking simulations were performed by using of Auto Dock 4 docking software.

\section{RESULTS AND DISCUSSION}

The physiological description of triazolo-thiadizoles derivatives and the use of guidelines linked to the druglike concept have found widespread acceptance as a means of reducing attraction to drug availability and development. ${ }^{8}$ Knowledge of the pharmacokinetic and pharmacodynamic properties of oral bioavailability, membrane detection and toxicity by a series of druglike molecules is a fundamental step in improving its composition, synthesis and biological use. One of the most important factors in selecting people who want to get oral drugs is to predict their absorption properties. It is generally accepted that some of the physicochemical explanations of drug molecules may be helpful in predicting drug absorption. Lipinski et al. ${ }^{9}$ proposed a "five-rule rule" which means that oral drugs must have (a) a molecular weight of less than 500 Dalton cells, (b) moderate lipophilicity (indicated by $\log \mathrm{P} \leq 5$ ), (c) a high number of -5 hydrogen bond donors and (d) a maximum number of ten hydrogen bond receivers In addition to the molecular components discussed in the Lipinski Act, other parameters have been used as a computer filter for liquid and oral detection.

The Table 1 Show that targeted compound with IUPAC Name. Results presented in Table 2 show that, with the exception of the parameter proposed by Palm, ${ }^{10}$ all selection computers are sufficient to predict fluid retention and oral detection and, therefore, can be considered drug-like molecules. In this study we also validated drug dosage, which includes drug dosage, lipophilicity, melting, molecular weight and toxic hazards in a single volume and this could be used to judge the overall computing power of a drug. ${ }^{11,12}$ As seen in the results collected in Table 2, the targeted compounds showed a moderate to effective dose of the drug (0.25-0.82) that demonstrated their lead-free chemical safety potential.

\section{Docking Score- more negative value indicates that higher binding affinity}

Docking Study As mentioned in the Introduction, the combination of the proposed chemicals with the active properties of the enzymes Ribosomal RNA subunit methyltransferase (1P91), PeriplasmicOligopeptideBinding Protein (1B05) and Protein-tyrosine phosphatona (type) (See the Figures 1-33). Document comparisons are performed using the Auto Dock system 4. The identified enzymes are shown in Table 2 this shows the negative amount of free energy. It is important to note, all computers except the D-3, F-2 and $\mathrm{H}-3$ (1B05) series have shown better intimacy than the binding site of the native ligand. Among them, the best binding findings have been reported to be antibacterial (B-3 C-4, I-1 and E-4), anti-inflammatory (B-2 and C-2), anti-diabetic (B- 3, B-4, C1, C-3, D-3, E-1, F1-, $\mathrm{H}-4$ and $\mathrm{J}-1)$. Another remarkable finding is that the excellent placement of the studied ligands found in this position is very similar to that of inhibitors. As all computers complete the process of obtaining good membranes, oral contraceptives, low toxicity and potential preventive functions. Docking Study When comparing Triazolo-thiadiazole derivatives with standard drug (K-1, K-2,K-3), derivative docking result is better. Ciprofloxacin, ibuprofen, and Acarbose have been used as standard drugs for antimicrobial, anti-inflammatory and anti-diabetic activity in comparative docking studies.

\section{CONCLUSION}

The present work is a bonafide and novel for the synthesis of derivatives of 2, 5 substituted triazolothiadiazole. The Docking studies indicate that the fuse ring of triazolo-thiazazole derivatives has proven to be a good Anti-diabetic molecule as well as antibacterial, 


\begin{tabular}{|c|c|c|c|}
\hline Comp. Name & Structure & IUPAC Name & M. F \\
\hline A-1 & & $\begin{array}{l}\text { 3-\{5-[1-(4-methylphenyl)-5-(pyrazin-2-yl)-4,5-dihydro-1H-1,2,4- } \\
\text { triazol-3-yl]-1,3,4-thiadiazol-2-yl\}benzoic acid }\end{array}$ & $\mathrm{C}_{22} \mathrm{H}_{17} \mathrm{~N}_{7} \mathrm{O}_{2} \mathrm{~S}$ \\
\hline A-2 & & $\begin{array}{c}\text { 3-\{5-[1-(2-hydroxyphenyl)-5-(pyrazin-2-yl)-4,5-dihydro-1H-1,2,4- } \\
\text { triazol-3-yl]-1,3,4-thiadiazol-2-yl\}benzoic acid }\end{array}$ & $\mathrm{C}_{21} \mathrm{H}_{15} \mathrm{~N}_{7} \mathrm{O}_{3} \mathrm{~S}$ \\
\hline A-3 & & 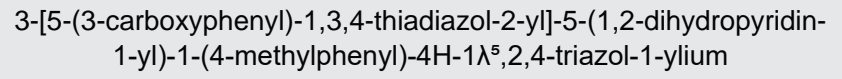 & $\mathrm{C}_{23} \mathrm{H}_{20} \mathrm{~N}_{6} \mathrm{O}_{2} \mathrm{~S}$ \\
\hline$A-4$ & & $\begin{array}{c}\text { 3-\{5-[5-(1,2-dihydropyridin-1-yl)-1-(2-hydroxyphenyl)-4,5-dihydro- } \\
\text { 1H-1,2,4-triazol-3-yl]-1,3,4-thiadiazol-2-yl\}benzoic acid }\end{array}$ & $\mathrm{C}_{22} \mathrm{H}_{18} \mathrm{~N}_{6} \mathrm{O}_{3} \mathrm{~S}$ \\
\hline B-1 & & $\begin{array}{c}\text { 3-chloro-5-\{5-[1-(4-methylphenyl)-5-(pyrazin-2-yl)-4,5-dihydro-1H- } \\
\text { 1,2,4-triazol-3-yl]-1,3,4-thiadiazol-2-yl\}benzoic acid }\end{array}$ & $\mathrm{C}_{22} \mathrm{H}_{16} \mathrm{ClN}_{7} \mathrm{O}_{2} \mathrm{~S}$ \\
\hline B-2 & & $\begin{array}{l}\text { 3-chloro-5-\{5-[1-(2-hydroxyphenyl)-5-(pyrazin-2-yl)-4,5-dihydro-1H- } \\
\text { 1,2,4-triazol-3-yl]-1,3,4-thiadiazol-2-yl\}benzoic acid }\end{array}$ & $\mathrm{C}_{21} \mathrm{H}_{14} \mathrm{ClN}_{7} \mathrm{O}_{3} \mathrm{~S}$ \\
\hline B-3 & & $\begin{array}{l}\text { 3-chloro-5-\{5-[5-(1,2-dihydropyridin-1-yl)-1-(4-methylphenyl)-4,5- } \\
\text { dihydro-1H-1,2,4-triazol-3-yl]-1,3,4-thiadiazol-2-yl\}benzoic acid }\end{array}$ & $\mathrm{C}_{23} \mathrm{H}_{19} \mathrm{ClN}_{6} \mathrm{O}_{2} \mathrm{~S}$ \\
\hline B-4 & & $\begin{array}{l}\text { 3-chloro-5-\{5-[5-(1,2-dihydropyridin-1-yl)-1-(2-hydroxyphenyl)-4,5- } \\
\text { dihydro-1H-1,2,4-triazol-3-yl]-1,3,4-thiadiazol-2-yl\}benzoic acid }\end{array}$ & $\mathrm{C}_{22} \mathrm{H}_{17} \mathrm{CIN}_{6} \mathrm{O}_{3} \mathrm{~S}$ \\
\hline C-1 & & $\begin{array}{l}\text { 2-hydroxy-5-\{5-[1-(4-methylphenyl)-5-(pyrazin-2-yl)-4,5-dihydro-1H- } \\
\text { 1,2,4-triazol-3-yl]-1,3,4-thiadiazol-2-yl\}benzoic acid }\end{array}$ & $\mathrm{C}_{22} \mathrm{H}_{17} \mathrm{~N}_{7} \mathrm{O}_{3} \mathrm{~S}$ \\
\hline C-2 & & $\begin{array}{c}\text { 2-hydroxy-5-\{5-[1-(2-hydroxyphenyl)-5-(pyrazin-2-yl)-4,5-dihydro- } \\
\text { 1H-1,2,4-triazol-3-yl]-1,3,4-thiadiazol-2-yl\}benzoic acid }\end{array}$ & $\mathrm{C}_{21} \mathrm{H}_{15} \mathrm{~N}_{7} \mathrm{O}_{4} \mathrm{~S}$ \\
\hline C-3 & & $\begin{array}{l}\text { 5-\{5-[5-(1,2-dihydropyridin-1-yl)-1-(4-methylphenyl)-4,5-dihydro-1H- } \\
\text { 1,2,4-triazol-3-yl]-1,3,4-thiadiazol-2-yl\}-2-hydroxybenzoic acid }\end{array}$ & $\mathrm{C}_{23} \mathrm{H}_{20} \mathrm{~N}_{6} \mathrm{O}_{3} \mathrm{~S}$ \\
\hline
\end{tabular}

Continued... 


\begin{tabular}{|c|c|c|c|}
\hline Comp. Name & Structure & IUPAC Name & M. F \\
\hline C-4 & & $\begin{array}{l}\text { 5-\{5-[5-(1,2-dihydropyridin-1-yl)-1-(2-hydroxyphenyl)-4,5-dihydro- } \\
1 \text { H-1,2,4-triazol-3-yl]-1,3,4-thiadiazol-2-yl\}-2-hydroxybenzoic acid }\end{array}$ & $\mathrm{C}_{22} \mathrm{H}_{18} \mathrm{~N}_{6} \mathrm{O}_{4} \mathrm{~S}$ \\
\hline D-1 & & $\begin{array}{l}\text { 4-\{5-[1-(4-methylphenyl)-5-(pyrazin-2-yl)-4,5-dihydro- } 1 \mathrm{H}-1,2,4- \\
\text { triazol-3-yl]-1,3,4-thiadiazol-2-yl\}benzene-1,2-dicarboxylic acid }\end{array}$ & $\mathrm{C}_{23} \mathrm{H}_{17} \mathrm{~N}_{7} \mathrm{O}_{4} \mathrm{~S}$ \\
\hline D-2 & & $\begin{array}{l}\text { 4-\{5-[1-(2-hydroxyphenyl)-5-(pyrazin-2-yl)-4,5-dihydro- } 1 \mathrm{H}-1,2,4- \\
\text { triazol-3-yl]-1,3,4-thiadiazol-2-yl\}benzene-1,2-dicarboxylic acid }\end{array}$ & $\mathrm{C}_{22} \mathrm{H}_{15} \mathrm{~N}_{7} \mathrm{O}_{5} \mathrm{~S}$ \\
\hline D-3 & & $\begin{array}{c}\text { 4-\{5-[5-(1,2-dihydropyridin-1-yl)-1-(4-methylphenyl)-4,5-dihydro- } \\
\text { 1H-1,2,4-triazol-3-yl]-1,3,4-thiadiazol-2-yl\}benzene-1,2-dicarboxylic } \\
\text { acid }\end{array}$ & $\mathrm{C}_{24} \mathrm{H}_{20} \mathrm{~N}_{6} \mathrm{O}_{4} \mathrm{~S}$ \\
\hline D-4 & & $\begin{array}{c}\text { 4-\{5-[5-(1,2-dihydropyridin-1-yl)-1-(4-methylphenyl)-4,5-dihydro- } \\
\text { 1H-1,2,4-triazol-3-yl]-1,3,4-thiadiazol-2-yl\}benzene-1,2-dicarboxylic } \\
\text { acid }\end{array}$ & $\mathrm{C}_{23} \mathrm{H}_{18} \mathrm{~N}_{6} \mathrm{O}_{5} \mathrm{~S}$ \\
\hline E-1 & & $\begin{array}{l}\text { 2,3,4-trihydroxy-5-\{5-[1-(4-methylphenyl)-5-(pyrazin-2-yl)-4,5- } \\
\text { dihydro-1H-1,2,4-triazol-3-yl]-1,3,4-thiadiazol-2-yl\}benzoic acid }\end{array}$ & $\mathrm{C}_{22} \mathrm{H}_{17} \mathrm{~N}_{7} \mathrm{O}_{5} \mathrm{~S}$ \\
\hline$E-2$ & & $\begin{array}{l}\text { 2,3,4-trihydroxy-5-\{5-[1-(2-hydroxyphenyl)-5-(pyrazin-2-yl)-4,5- } \\
\text { dihydro-1H-1,2,4-triazol-3-yl]-1,3,4-thiadiazol-2-yl\}benzoic acid }\end{array}$ & $\mathrm{C}_{21} \mathrm{H}_{15} \mathrm{~N}_{7} \mathrm{O}_{6} \mathrm{~S}$ \\
\hline E-3 & & $\begin{array}{l}\text { 5-\{5-[5-(1,2-dihydropyridin-1-yl)-1-(4-methylphenyl)-4,5-dihydro-1H- } \\
\text { 1,2,4-triazol-3-yl]-1,3,4-thiadiazol-2-yl\}-2,3,4-trihydroxybenzoic acid }\end{array}$ & $\mathrm{C}_{23} \mathrm{H}_{20} \mathrm{~N}_{6} \mathrm{O}_{5} \mathrm{~S}$ \\
\hline$E-4$ & & $\begin{array}{c}\text { 5-\{5-[5-(1,2-dihydropyridin-1-yl)-1-(2-hydroxyphenyl)-4,5-dihydro- } \\
\text { 1H-1,2,4-triazol-3-yl]-1,3,4-thiadiazol-2-yl\}-2,3,4-trihydroxybenzoic } \\
\text { acid }\end{array}$ & $\mathrm{C}_{22} \mathrm{H}_{18} \mathrm{~N}_{6} \mathrm{O}_{6} \mathrm{~S}$ \\
\hline F-1 & & $\begin{array}{l}\text { 3-\{5-[1-(4-methylphenyl)-5-(pyrazin-2-yl)-4,5-dihydro-1H-1,2,4- } \\
\text { triazol-3-yl]-1,3,4-thiadiazol-2-yl\}-5-nitrobenzoic acid }\end{array}$ & $\mathrm{C}_{22} \mathrm{H}_{16} \mathrm{~N}_{8} \mathrm{O}_{4} \mathrm{~S}$ \\
\hline $\mathrm{F}-2$ & & $\begin{array}{c}3-\{5-[1-(2-h y d r o x y p h e n y l)-5-(\text { pyrazin-2-yl)-4,5-dihydro-1H-1,2,4- } \\
\text { triazol-3-yl]-1,3,4-thiadiazol-2-yl\}-5-nitrobenzoic acid }\end{array}$ & $\mathrm{C}_{21} \mathrm{H}_{14} \mathrm{~N}_{8} \mathrm{O}_{5} \mathrm{~S}$ \\
\hline
\end{tabular}

Continued... 


\begin{tabular}{|c|c|c|c|}
\hline Comp. Name & Structure & IUPAC Name & M. F \\
\hline $\mathrm{F}-3$ & & $\begin{array}{l}\text { 3-\{5-[5-(1,2-dihydropyridin-1-yl)-1-(4-methylphenyl)-4,5-dihydro-1H- } \\
\text { 1,2,4-triazol-3-yl]-1,3,4-thiadiazol-2-yl\}-5-nitrobenzoic acid }\end{array}$ & $\mathrm{C}_{23} \mathrm{H}_{19} \mathrm{~N}_{7} \mathrm{O}_{4} \mathrm{~S}$ \\
\hline$F-4$ & & $\begin{array}{l}\text { 3-\{5-[5-(1,2-dihydropyridin-1-yl)-1-(2-hydroxyphenyl)-4,5-dihydro- } \\
\text { 1H-1,2,4-triazol-3-yl]-1,3,4-thiadiazol-2-yl\}-5-nitrobenzoic acid }\end{array}$ & $\mathrm{C}_{22} \mathrm{H}_{17} \mathrm{~N}_{7} \mathrm{O}_{5} \mathrm{~S}$ \\
\hline G-1 & & $\begin{array}{l}\text { methyl 2-hydroxy-5-\{5-[1-(4-methylphenyl)-5-(pyrazin-2-yl)-4,5- } \\
\text { dihydro-1H-1,2,4-triazol-3-yl]-1,3,4-thiadiazol-2-yl\}benzoate }\end{array}$ & $\mathrm{C}_{23} \mathrm{H}_{19} \mathrm{~N}_{7} \mathrm{O}_{3} \mathrm{~S}$ \\
\hline G-2 & & $\begin{array}{l}\text { methyl 2-hydroxy-5-\{5-[1-(2-hydroxyphenyl)-5-(pyrazin-2-yl)-4,5- } \\
\text { dihydro-1H-1,2,4-triazol-3-yl]-1,3,4-thiadiazol-2-yl\}benzoate }\end{array}$ & $\mathrm{C}_{22} \mathrm{H}_{17} \mathrm{~N}_{7} \mathrm{O}_{4} \mathrm{~S}$ \\
\hline G-3 & & $\begin{array}{l}\text { methyl 5-\{5-[5-(1,2-dihydropyridin-1-yl)-1-(4-methylphenyl)- } \\
\text { 4,5-dihydro-1H-1,2,4-triazol-3-yl]-1,3,4-thiadiazol-2-yl\}-2- } \\
\text { hydroxybenzoate }\end{array}$ & $\mathrm{C}_{24} \mathrm{H}_{22} \mathrm{~N}_{6} \mathrm{O}_{3} \mathrm{~S}$ \\
\hline G-4 & & $\begin{array}{c}\text { methyl 5-\{5-[5-(1,2-dihydropyridin-1-yl)-1-(2-hydroxyphenyl)- } \\
\text { 4,5-dihydro-1H-1,2,4-triazol-3-yl]-1,3,4-thiadiazol-2-yl\}-2- } \\
\text { hydroxybenzoate }\end{array}$ & $\mathrm{C}_{23} \mathrm{H}_{20} \mathrm{~N}_{6} \mathrm{O}_{4} \mathrm{~S}$ \\
\hline $\mathrm{H}-1$ & & $\begin{array}{l}\text { 2-(acetyloxy)-6-\{5-[1-(4-methylphenyl)-5-(pyrazin-2-yl)-4,5-dihydro- } \\
\text { 1H-1,2,4-triazol-3-yl]-1,3,4-thiadiazol-2-yl\}benzoic acid }\end{array}$ & $\mathrm{C}_{24} \mathrm{H}_{19} \mathrm{~N}_{7} \mathrm{O}_{4} \mathrm{~S}$ \\
\hline $\mathrm{H}-2$ & & $\begin{array}{l}\text { 2-(acetyloxy)-6-\{5-[1-(2-hydroxyphenyl)-5-(pyrazin-2-yl)-4,5- } \\
\text { dihydro-1H-1,2,4-triazol-3-yl]-1,3,4-thiadiazol-2-yl\}benzoic acid }\end{array}$ & $\mathrm{C}_{23} \mathrm{H}_{17} \mathrm{~N}_{7} \mathrm{O}_{5} \mathrm{~S}$ \\
\hline $\mathrm{H}-3$ & & $\begin{array}{l}\text { 2-(acetyloxy)-6-\{5-[5-(1,2-dihydropyridin-1-yl)-1-(4-methylphenyl)- } \\
\text { 4,5-dihydro-1H-1,2,4-triazol-3-yl]-1,3,4-thiadiazol-2-yl\}benzoic acid }\end{array}$ & $\mathrm{C}_{25} \mathrm{H}_{22} \mathrm{~N}_{6} \mathrm{O}_{4} \mathrm{~S}$ \\
\hline $\mathrm{H}-4$ & & $\begin{array}{l}\text { 2-(acetyloxy)-6-\{5-[5-(1,2-dihydropyridin-1-yl)-1-(2-hydroxyphenyl)- } \\
\text { 4,5-dihydro-1H-1,2,4-triazol-3-yl]-1,3,4-thiadiazol-2-yl\}benzoic acid }\end{array}$ & $\mathrm{C}_{23} \mathrm{H}_{18} \mathrm{~N}_{6} \mathrm{O}_{5} \mathrm{~S}$ \\
\hline I-1 & & $\begin{array}{c}\text { 3-hydroxy-5-\{5-[1-(4-methylphenyl)-5-(pyrazin-2-yl)-4,5-dihydro-1H- } \\
\text { 1,2,4-triazol-3-yl]-1,3,4-thiadiazol-2-yl\}benzoic acid }\end{array}$ & $\mathrm{C}_{22} \mathrm{H}_{17} \mathrm{~N}_{7} \mathrm{O}_{3} \mathrm{~S}$ \\
\hline
\end{tabular}

Continued... 


\begin{tabular}{|c|c|c|c|}
\hline Comp. Name & Structure & IUPAC Name & M. F \\
\hline $1-2$ & & $\begin{array}{l}\text { 3-hydroxy-5-\{5-[1-(2-hydroxyphenyl)-5-(pyrazin-2-yl)-4,5-dihydro- } \\
\text { 1H-1,2,4-triazol-3-yl]-1,3,4-thiadiazol-2-yl\}benzoic acid }\end{array}$ & $\mathrm{C}_{21} \mathrm{H}_{15} \mathrm{~N}_{7} \mathrm{O}_{4} \mathrm{~S}$ \\
\hline I-3 & & $\begin{array}{c}\text { 3-\{5-[5-(1,2-dihydropyridin-1-yl)-1-(4-methylphenyl)-4,5-dihydro-1H- } \\
\text { 1,2,4-triazol-3-yl]-1,3,4-thiadiazol-2-yl\}-5-hydroxybenzoic acid }\end{array}$ & $\mathrm{C}_{23} \mathrm{H}_{20} \mathrm{~N}_{6} \mathrm{O}_{3} \mathrm{~S}$ \\
\hline |-4 & & $\begin{array}{l}\text { 3-\{5-[5-(1,2-dihydropyridin-1-yl)-1-(2-hydroxyphenyl)-4,5-dihydro- } \\
\text { 1H-1,2,4-triazol-3-yl]-1,3,4-thiadiazol-2-yl\}-5-hydroxybenzoic acid }\end{array}$ & $\mathrm{C}_{22} \mathrm{H}_{18} \mathrm{~N}_{6} \mathrm{O}_{4} \mathrm{~S}$ \\
\hline $\mathrm{J}-1$ & & $\begin{array}{c}\text { 4-hydroxy-3-\{5-[1-(4-methylphenyl)-5-(pyrazin-2-yl)-4,5-dihydro-1H- } \\
\text { 1,2,4-triazol-3-yl]-1,3,4-thiadiazol-2-yl\}benzoic acid }\end{array}$ & $\mathrm{C}_{22} \mathrm{H}_{17} \mathrm{~N}_{7} \mathrm{O}_{3} \mathrm{~S}$ \\
\hline $\mathrm{J}-2$ & & $\begin{array}{c}\text { 4-hydroxy-3-\{5-[1-(2-hydroxyphenyl)-5-(pyrazin-2-yl)-4,5-dihydro- } \\
\text { 1H-1,2,4-triazol-3-yl]-1,3,4-thiadiazol-2-yl\}benzoic acid }\end{array}$ & $\mathrm{C}_{21} \mathrm{H}_{15} \mathrm{~N}_{7} \mathrm{O}_{4} \mathrm{~S}$ \\
\hline $\mathrm{J}-3$ & & $\begin{array}{l}\text { 3-\{5-[5-(1,2-dihydropyridin-1-yl)-1-(4-methylphenyl)-4,5-dihydro-1H- } \\
\text { 1,2,4-triazol-3-yl]-1,3,4-thiadiazol-2-yl\}-4-hydroxybenzoic acid }\end{array}$ & $\mathrm{C}_{23} \mathrm{H}_{20} \mathrm{~N}_{6} \mathrm{O}_{3} \mathrm{~S}$ \\
\hline $\mathrm{J}-4$ & & $\begin{array}{l}\text { 3-\{5-[5-(1,2-dihydropyridin-1-yl)-1-(2-hydroxyphenyl)-4,5-dihydro- } \\
\text { 1H-1,2,4-triazol-3-yl]-1,3,4-thiadiazol-2-yl\}-4-hydroxybenzoic acid }\end{array}$ & $\mathrm{C}_{22} \mathrm{H}_{18} \mathrm{~N}_{6} \mathrm{O}_{4} \mathrm{~S}$ \\
\hline $\mathrm{K}-1$ & & 3-(diaminomethylidene)-1,1-dimethylguanidine & $\mathrm{C}_{4} \mathrm{H}_{11} \mathrm{~N}_{5}$ \\
\hline $\mathrm{K}-2$ & & $\begin{array}{l}\text { 1-cyclopropyl-6-fluoro-4-oxo-7-piperazin-1-ylquinoline-3-carboxylic } \\
\text { acid }\end{array}$ & $\mathrm{C}_{17} \mathrm{H}_{18} \mathrm{FN}_{3} \mathrm{O}_{3}$ \\
\hline K-3 & & 2-[4-(2 methylpropyl)phenyl] propanoic acid & $\mathrm{C}_{13} \mathrm{H}_{18} \mathrm{O}_{2}$ \\
\hline
\end{tabular}




\begin{tabular}{|c|c|c|c|c|c|c|c|c|}
\hline \multirow[t]{2}{*}{ Co. } & \multirow{2}{*}{$\begin{array}{c}M W \\
<500\end{array}$} & \multirow{2}{*}{$\begin{array}{c}\text { HBA } \\
<10\end{array}$} & \multirow{2}{*}{$\begin{array}{c}H B D \\
<5\end{array}$} & \multirow{2}{*}{$\begin{array}{c}\log P \\
\leq 5\end{array}$} & \multirow{2}{*}{$\begin{array}{c}P S A \\
\leq 140\end{array}$} & \multicolumn{3}{|c|}{ Docking Score } \\
\hline & & & & & & 1Q6S & 1P91 & 1B05 \\
\hline A-1 & 443.48 & 7 & 2 & 1.97 & 124.73 & -10.3 & -9.4 & -7.0 \\
\hline A-2 & 445.45 & 8 & 3 & 1.82 & 124.96 & -10.1 & -9.8 & -8.5 \\
\hline$A-3$ & 443.42 & 5 & 2 & 3.20 & 122.19 & -10.1 & -9.9 & -6.8 \\
\hline$A-4$ & 446.48 & 6 & 3 & 2.96 & 132.42 & -10.5 & -10.5 & -7.7 \\
\hline B-1 & 477.93 & 7 & 2 & 2.63 & 134.73 & -8.1 & -9.4 & -4.8 \\
\hline B-2 & 479.90 & 8 & 3 & 2.35 & 134.96 & -10.2 & -10.1 & -8.9 \\
\hline B-3 & 478.95 & 5 & 2 & 3.27 & 122.19 & -10.6 & -10.5 & -5.9 \\
\hline B-4 & 480.30 & 6 & 3 & 3.34 & 122.4 & -10.6 & -9.6 & -8.0 \\
\hline C-1 & 459.48 & 8 & 3 & 1.35 & 124.96 & -10.6 & -9.3 & -7.0 \\
\hline $\mathrm{C}-2$ & 461.45 & 9 & 4 & 1.89 & 125.19 & -9.8 & -9.9 & -8.6 \\
\hline $\mathrm{C}-3$ & 460.51 & 6 & 3 & 2.59 & 122.42 & -10.7 & -9.5 & -6.1 \\
\hline$C-4$ & 462.48 & 7 & 4 & 2.91 & 122.65 & -10.3 & -10.1 & -7.9 \\
\hline D-1 & 487.49 & 9 & 3 & 1.82 & 122.03 & -8.4 & -9.7 & -6.9 \\
\hline D-2 & 489.46 & 10 & 4 & 1.43 & 102.26 & -9.1 & -9.9 & -1.4 \\
\hline D-3 & 488.52 & 7 & 3 & 2.87 & 129.49 & -10.7 & -7.4 & -6.2 \\
\hline D-4 & 490.49 & 8 & 4 & 2.14 & 129.72 & -7.4 & -9.0 & -5.2 \\
\hline E-1 & 491.48 & 10 & 5 & 1.75 & 105.42 & -10.5 & -8.3 & -6.1 \\
\hline E-2 & 493.45 & 11 & 5 & 1.40 & 125.65 & -9.9 & -9.6 & -5.3 \\
\hline E-3 & 492.51 & 8 & 5 & 2.88 & 182.88 & -10.3 & -9.5 & -6.2 \\
\hline E-4 & 494.48 & 9 & 5 & 2.21 & 103.03 & -8.8 & -9.9 & -4.9 \\
\hline F-1 & 488.48 & 9 & 2 & 1.90 & 120.55 & -10.6 & -9.1 & -6.6 \\
\hline $\mathrm{F}-2$ & 490.45 & 10 & 3 & 1.24 & 110.78 & -10.3 & -9.1 & -0.9 \\
\hline $\mathrm{F}-3$ & 489.51 & 7 & 2 & 2.76 & 128.01 & -10.6 & -9.3 & -6.5 \\
\hline $\mathrm{F}-4$ & 491.48 & 8 & 3 & 2.25 & 128.24 & -8.6 & -10.3 & -6.3 \\
\hline G-1 & 473.51 & 8 & 2 & 2.94 & 123.96 & -10.4 & -9.0 & -4.3 \\
\hline G-2 & 475.48 & 9 & 9 & 2.83 & 124.19 & -10.2 & -8.1 & -2.4 \\
\hline G-3 & 474.53 & 6 & 2 & 3.56 & 121.42 & -10.3 & -9.1 & -6.5 \\
\hline G-4 & 476.51 & 7 & 3 & 3.62 & 121.65 & -10.5 & -8.9 & -4.8 \\
\hline $\mathrm{H}-1$ & 491.52 & 9 & 2 & 2.16 & 121.00 & -8.4 & -8.4 & -4.3 \\
\hline $\mathrm{H}-2$ & 493.49 & 10 & 3 & 2.00 & 121.26 & -9.0 & -8.7 & -5.5 \\
\hline $\mathrm{H}-3$ & 492.54 & 7 & 7 & 3.41 & 128.49 & -9.6 & -8.8 & -1.3 \\
\hline $\mathrm{H}-4$ & 490.49 & 8 & 3 & 2.65 & 128.72 & -9.8 & -8.7 & -6.2 \\
\hline $\mathrm{I}-1$ & 459.48 & 8 & 3 & 2.11 & 124.96 & -8.9 & -10.0 & -7.0 \\
\hline $\mathrm{I}-2$ & 461.45 & 9 & 4 & 4.73 & 125.19 & -8.9 & -9.9 & -8.2 \\
\hline I-3 & 460.51 & 6 & 3 & 3.01 & 122.42 & -8.6 & -9.6 & -7.2 \\
\hline $\mathrm{I}-4$ & 462.48 & 7 & 4 & 2.76 & 132.65 & -9.5 & -9.6 & -5.1 \\
\hline J-1 & 449.48 & 8 & 3 & 2.21 & 124.96 & -10.3 & -9.1 & -8.1 \\
\hline $\mathrm{J}-2$ & 461.45 & 9 & 4 & 2.05 & 125.19 & -9.7 & -8.5 & -4.9 \\
\hline $\mathrm{J}-3$ & 460.51 & 6 & 3 & 2.93 & 122.42 & -8.9 & -9.1 & -6.1 \\
\hline $\mathrm{J}-4$ & 462.48 & 7 & 4 & 2.83 & 122.65 & -8.7 & -9.2 & -7.7 \\
\hline $\mathrm{K}-1$ & 129.16 & 2 & 3 & 0.34 & 91.49 & -7.3 & $\ldots$ & $\ldots$. \\
\hline $\mathrm{K}-2$ & 331.34 & 5 & 2 & 2.24 & 74.57 & $\ldots$ & -7.8 & $\ldots$ \\
\hline $\mathrm{K}-3$ & 206.28 & 2 & 1 & 2.36 & 37.30 & $\ldots \ldots$ & $\ldots \ldots$ & -4.5 \\
\hline
\end{tabular}

* M.W - Molecular weight, HBA - number of hydrogen bond acceptors, HBD - number of hydrogen bond donor, PSA - polar surface area in $\AA$. Log p - logarithm of compound partition. 


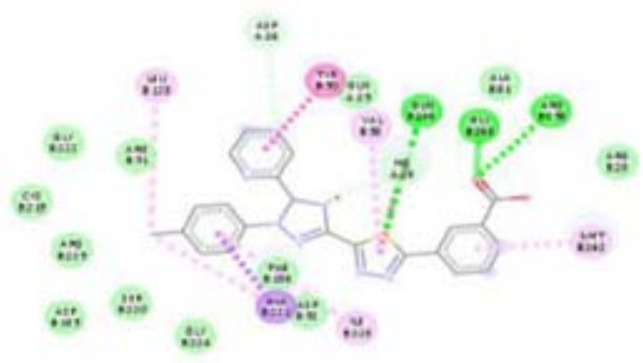

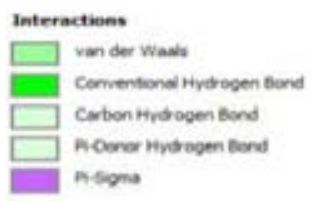

Figure 1: A-1 1Q6S Receptor- Ligand 2D diagram.

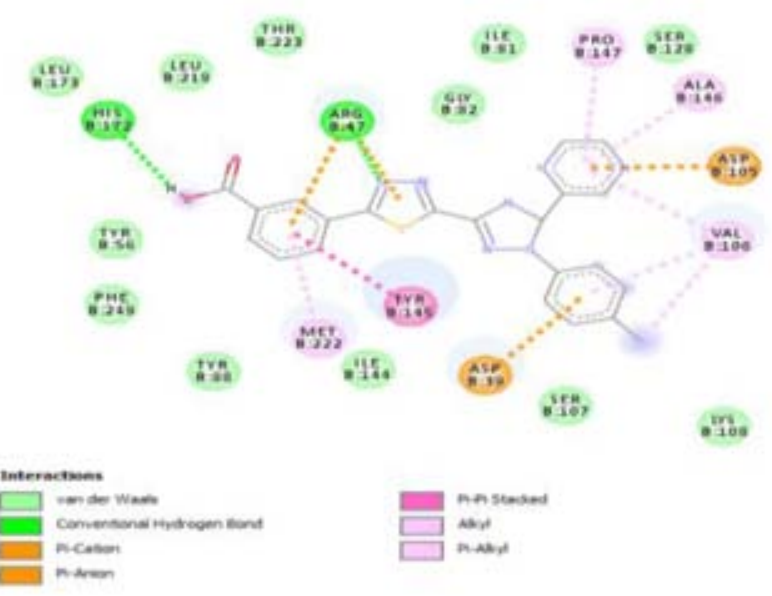

Figure 2 : A-1 1P91 Receptor- Ligand 2D diagram.
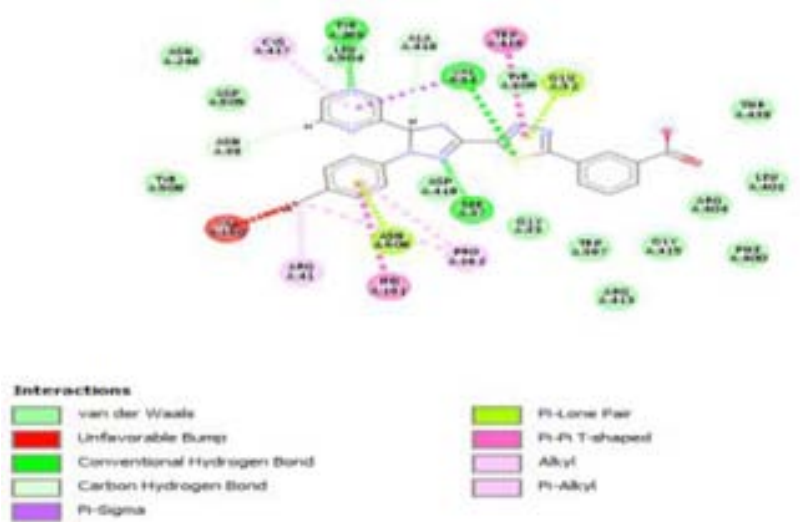

Figure 3: A-1 1B05 Receptor- Ligand 2D diagram.

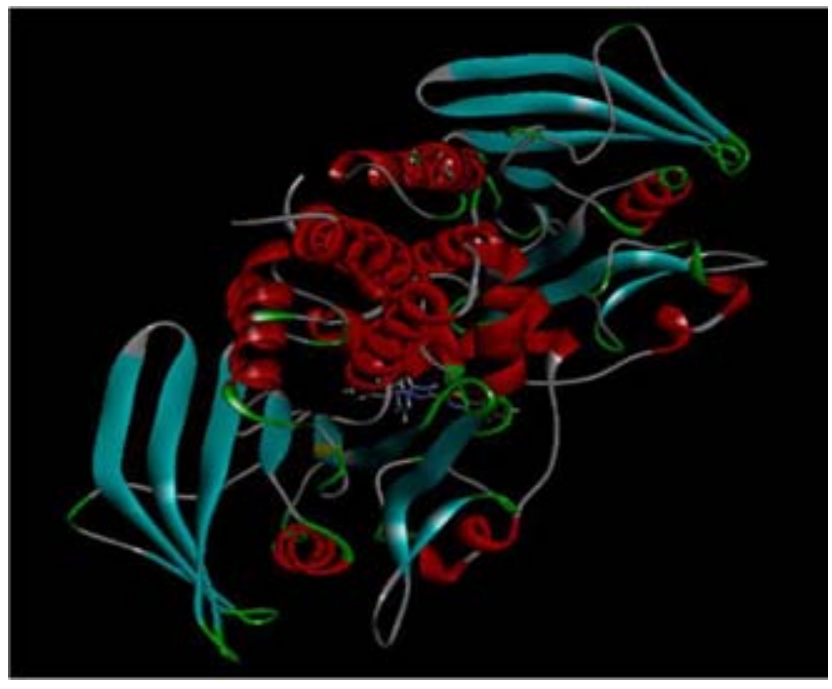

Figure 1A: A-1 1Q6S Receptor-Ligand Interaction.

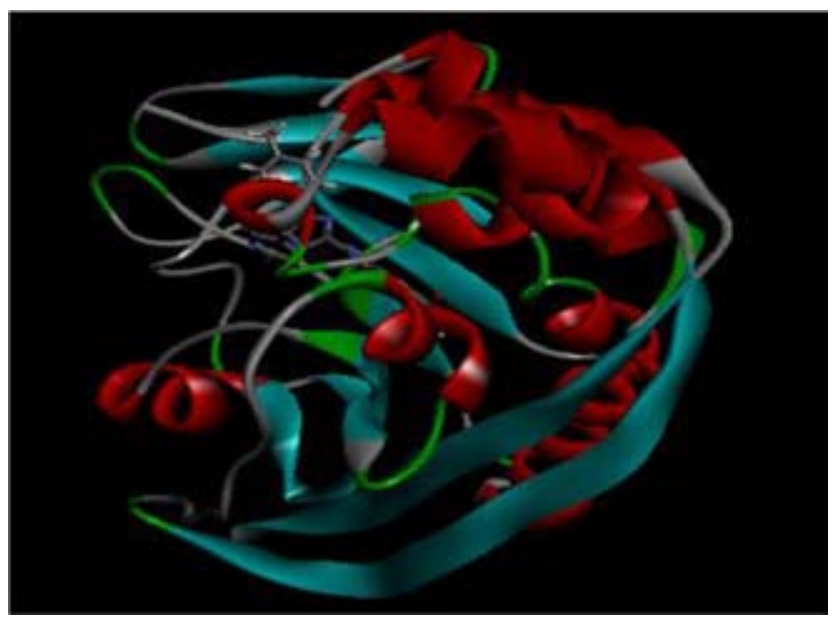

Figure 2A: A-1 1P91 Receptor-Ligand Interaction.

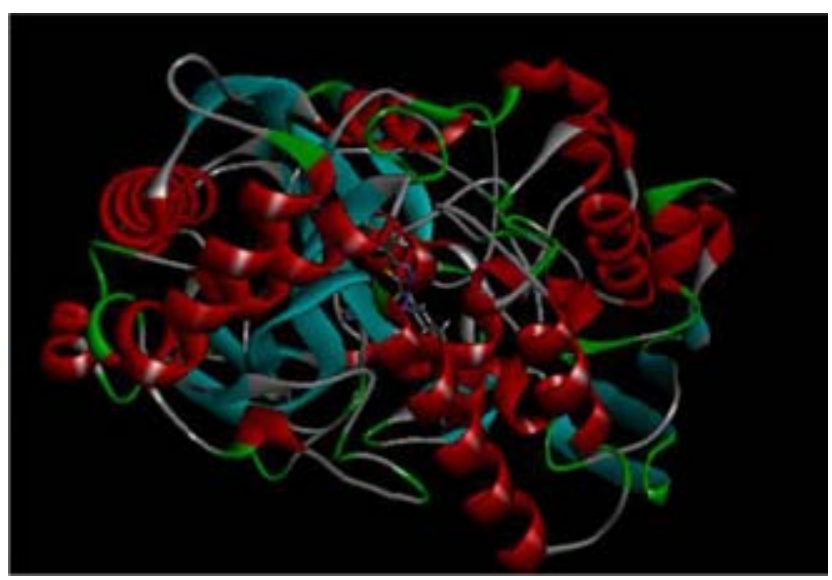

Figure 3A: A-1 1B05 Receptor-Ligand Interaction. 


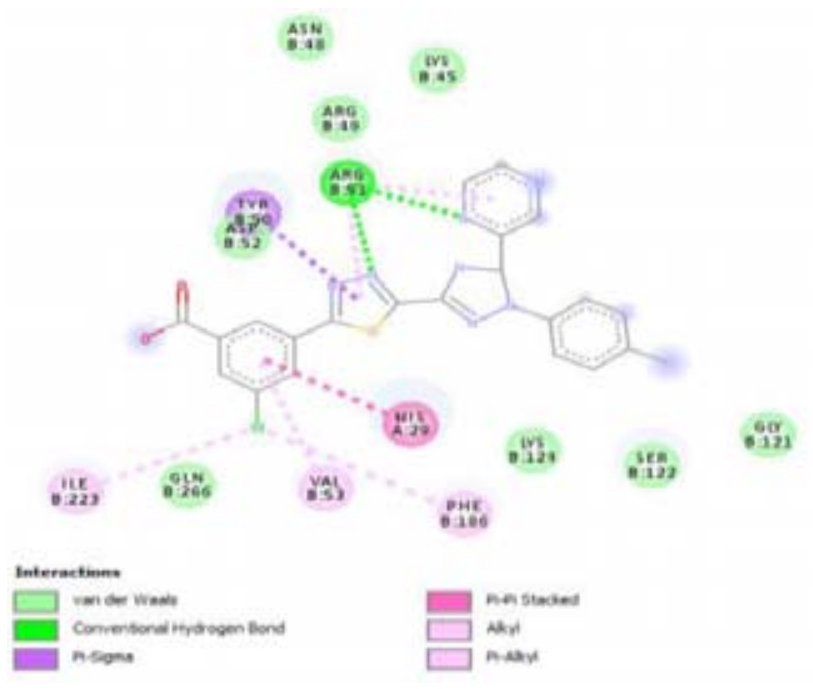

Figure 4: B-1 1Q6S Receptor- Ligand 2D diagram.

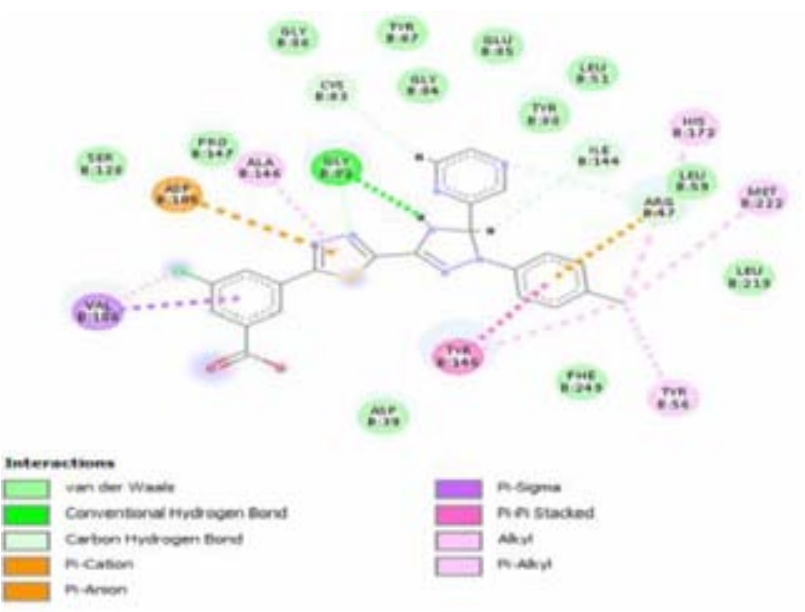

Figure 5: B-1 1P91 Receptor- Ligand 2D diagram.
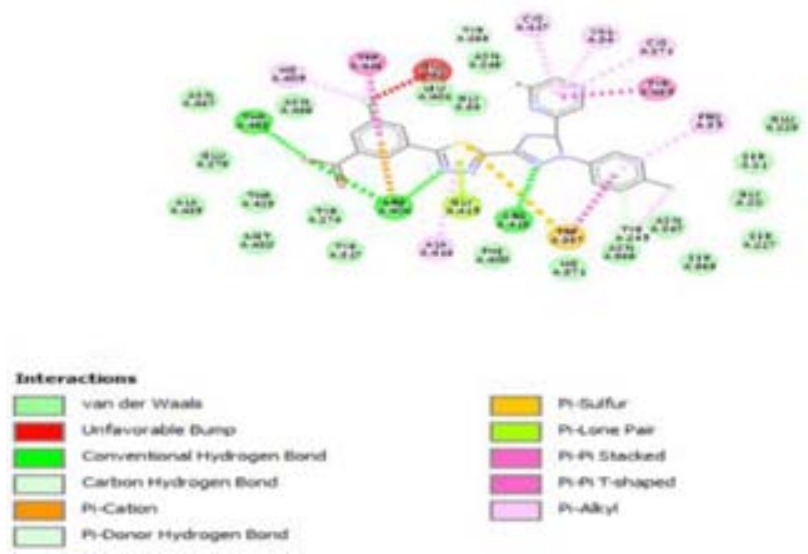

Figure 6: B-1 1B05 Receptor- Ligand 2D diagram.

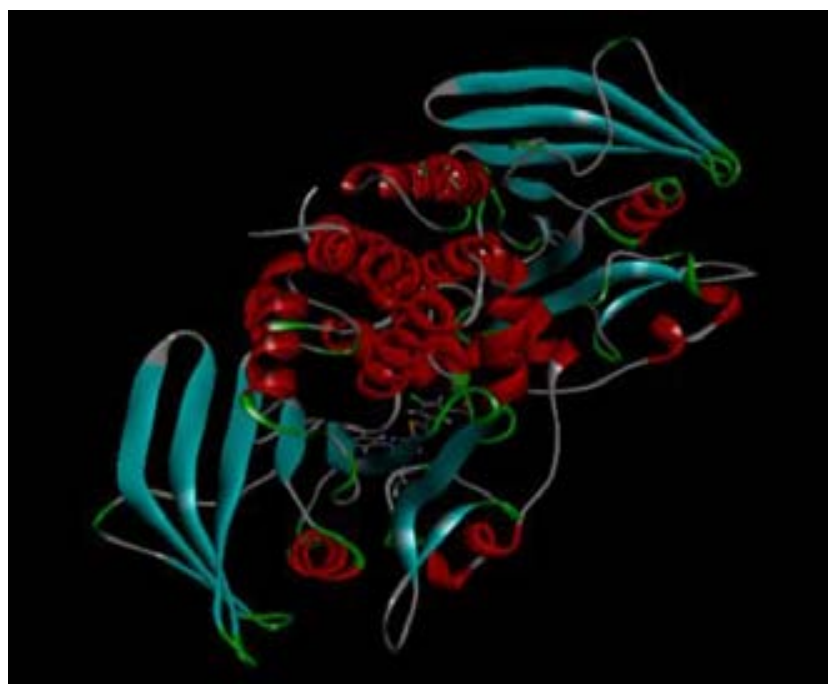

Figure 4A: B-1 1Q6S Receptor-Ligand Interaction.

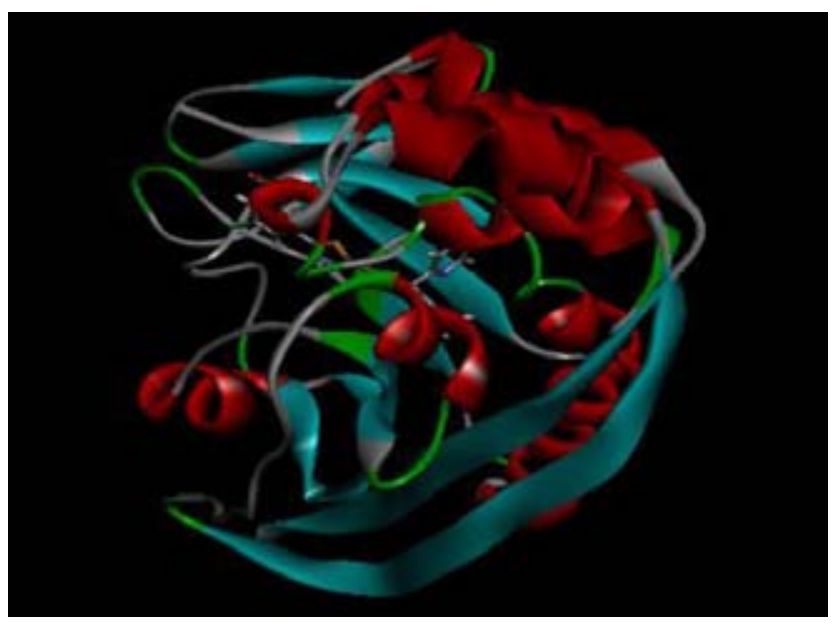

Figure 5A: B-1 1P91 Receptor-Ligand Interaction.

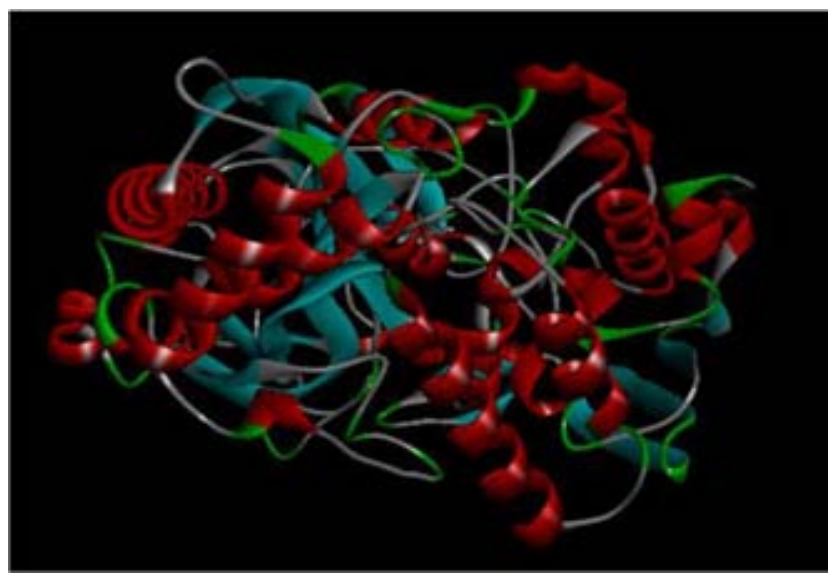

Figure 6A: B-1 1B05 Receptor-Ligand Interaction. 


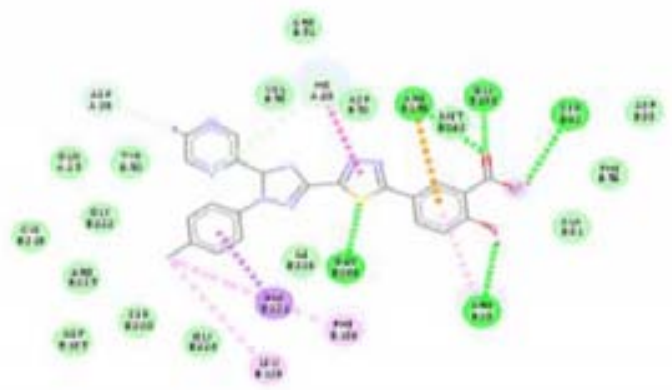

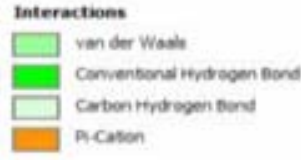

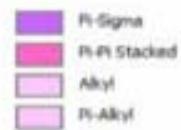

Figure 7: C-1 1Q6S Receptor- Ligand 2D diagram.

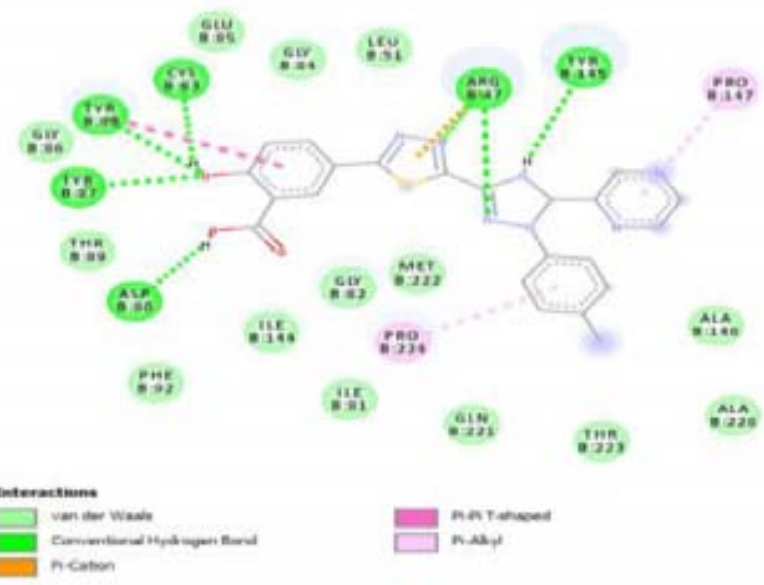

Figure 8: C-1 1P91 Receptor- Ligand 2D diagram.
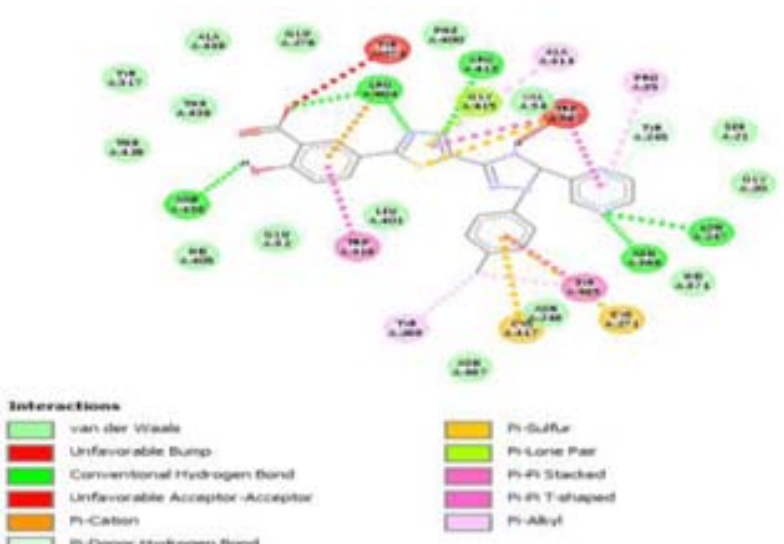

Figure 9: C-1 1B05 Receptor- Ligand 2D diagram.

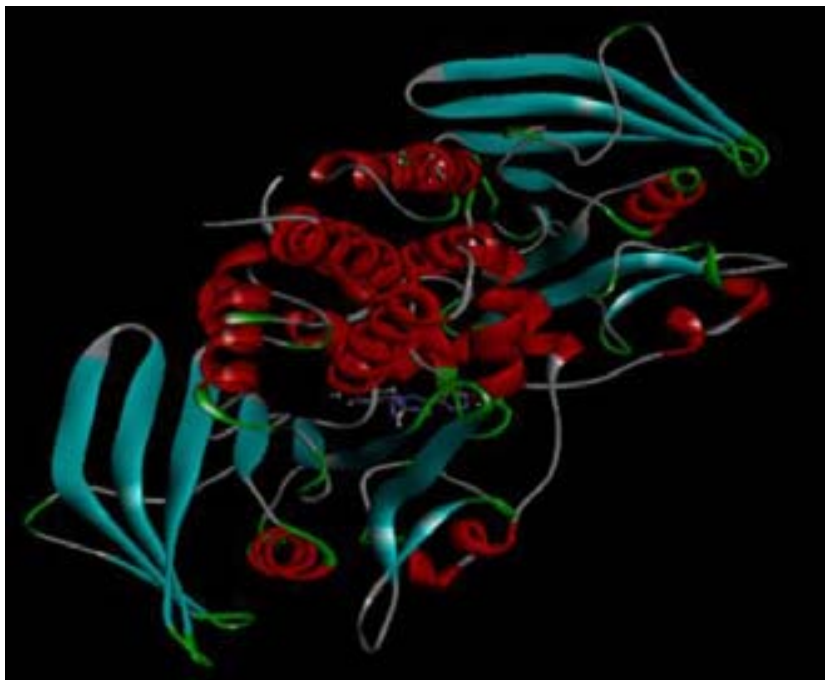

Figure 7A: C-1 1Q6S Receptor-Ligand Interaction.

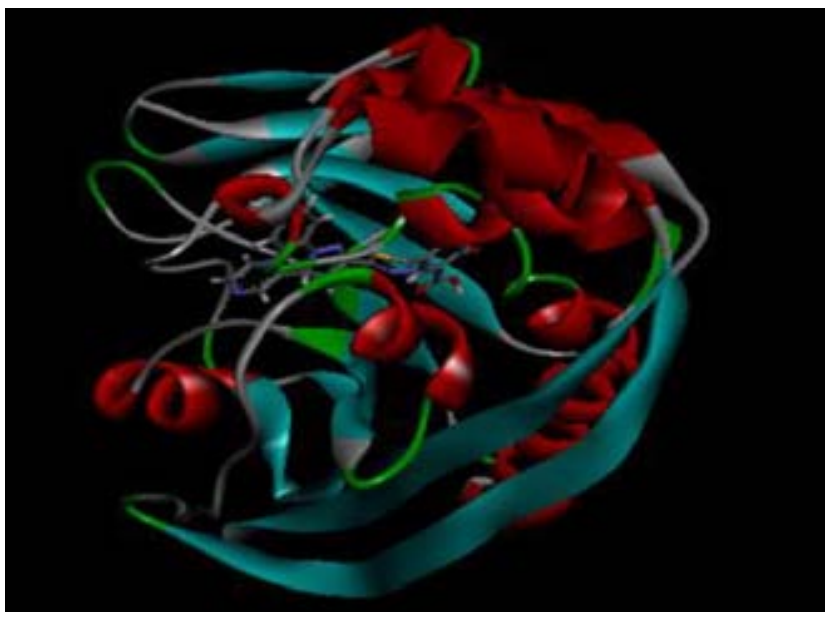

Figure 8A: C-1 1P91 Receptor-Ligand Interaction.

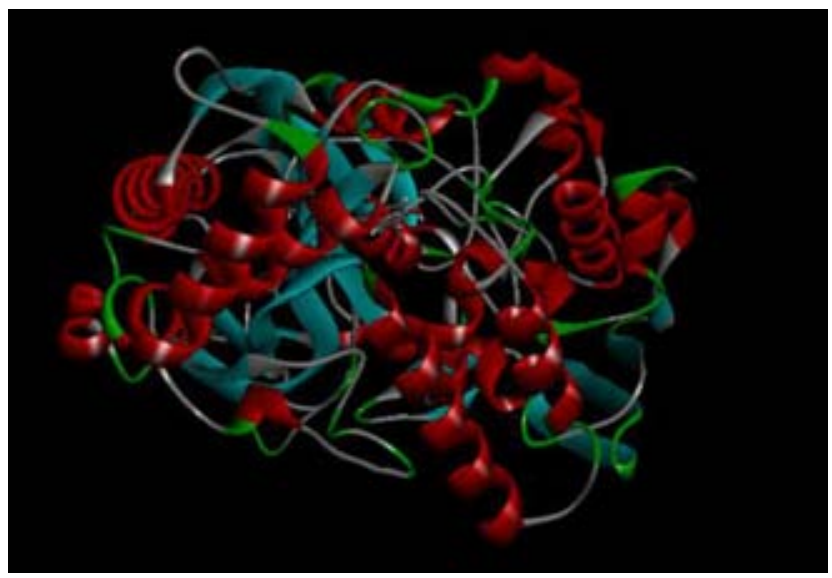

Figure 9A: C-1 1B05 Receptor-Ligand Interaction. 


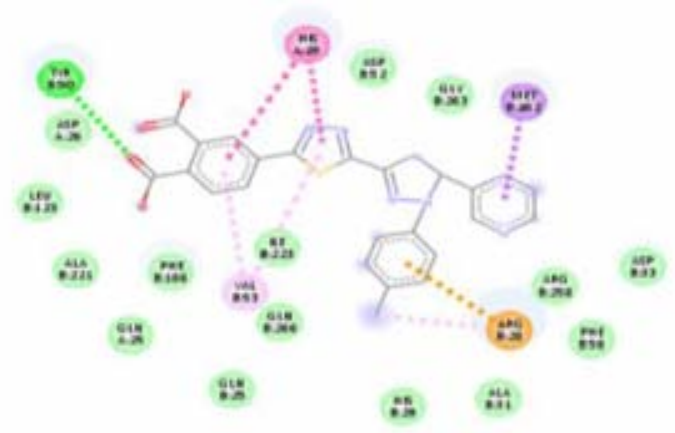

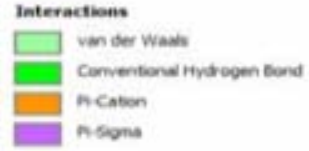

Figure 10: D-1 1Q6S Receptor- Ligand 2D diagram.

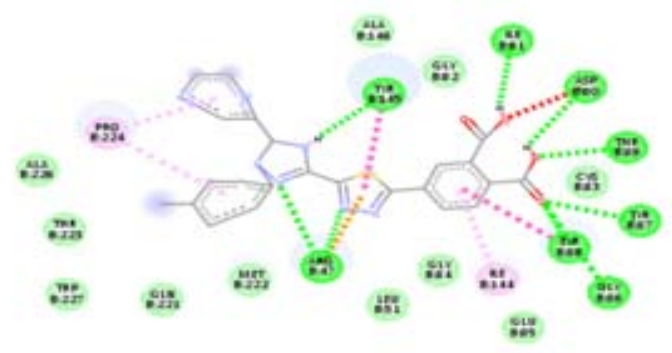

Internctions

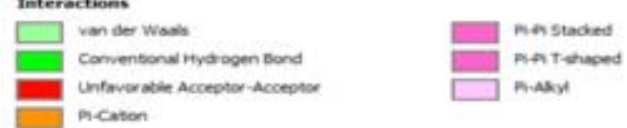

Figure 11: D-1 1P91 Receptor- Ligand 2D diagram.

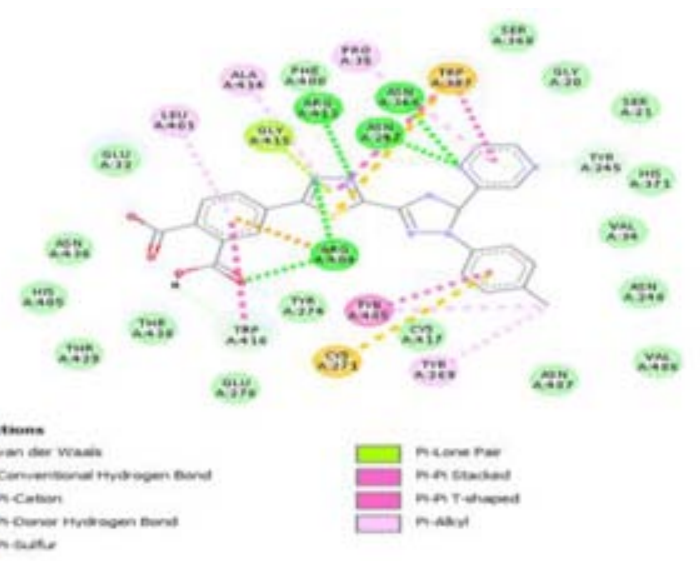

Figure 12: D-1 1B05 Receptor- Ligand 2D diagram.

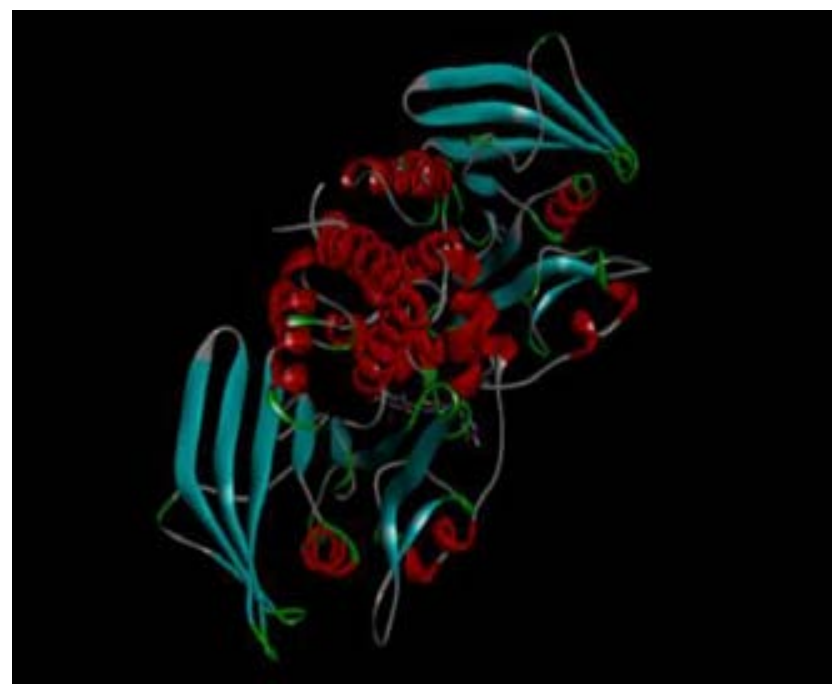

Figure 10A: D-1 1Q6S Receptor-Ligand Interaction.

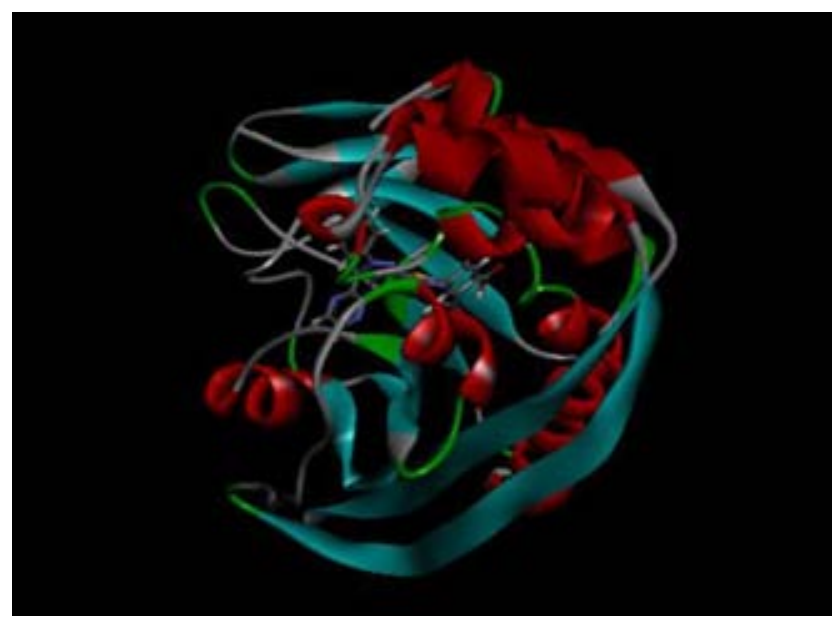

Figure 11A: D-1 1P91 Receptor-Ligand Interaction.

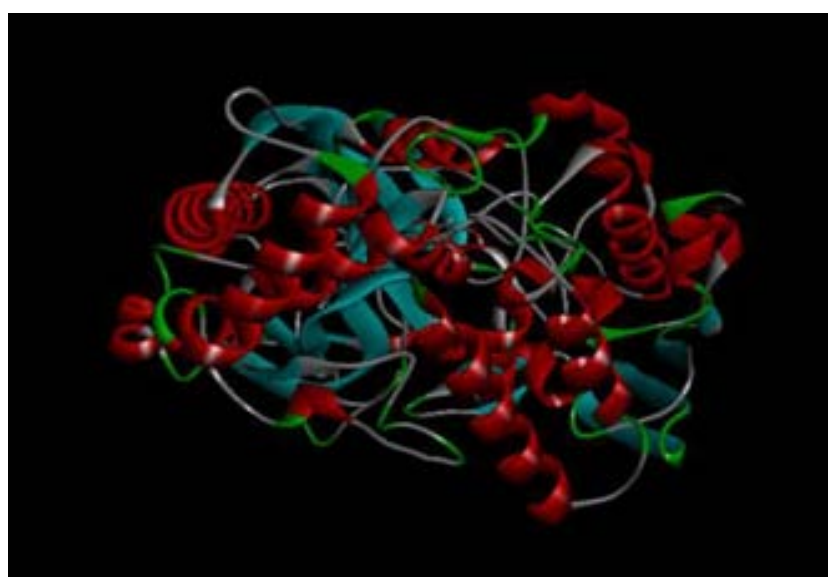

Figure 12A: D-1 1B05 Receptor-Ligand Interaction. 


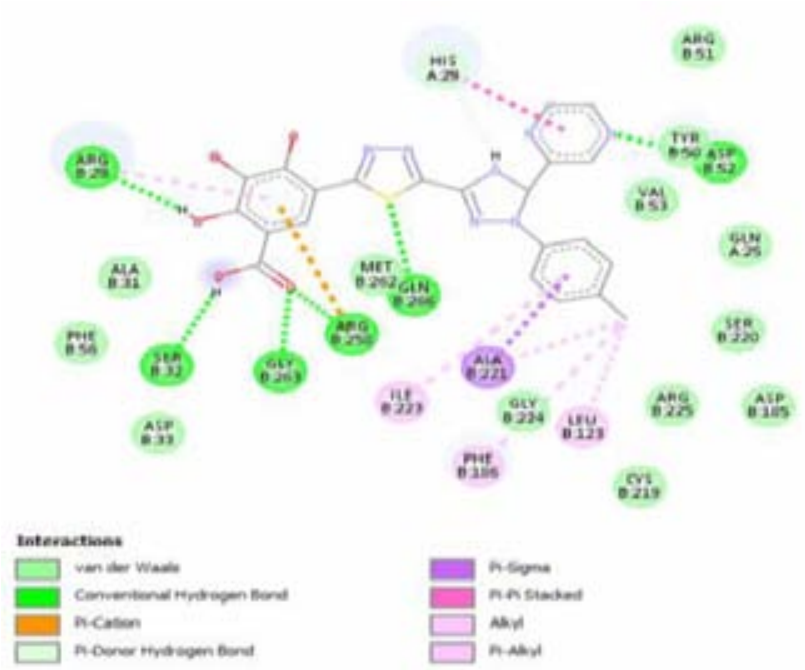

Figure 13: E-1 1Q6S Receptor- Ligand 2D diagram.

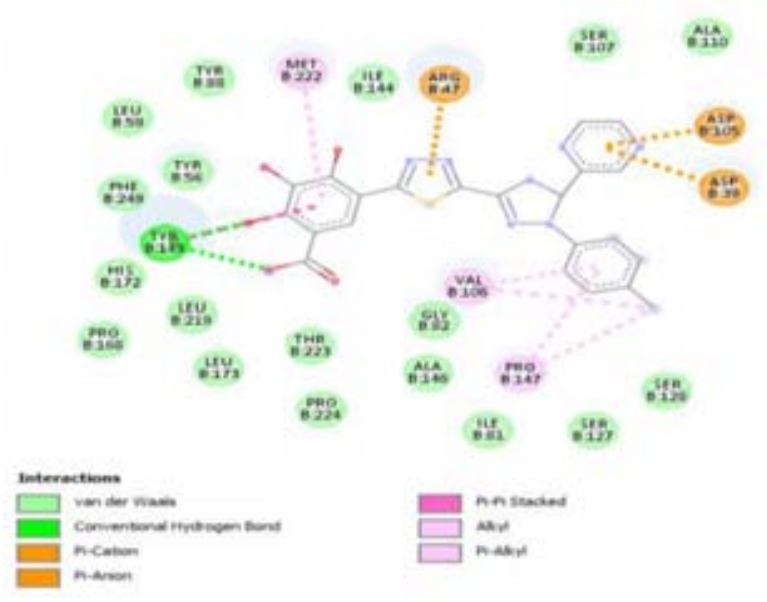

Figure 14: E-1 1P91 Receptor- Ligand 2D diagram.
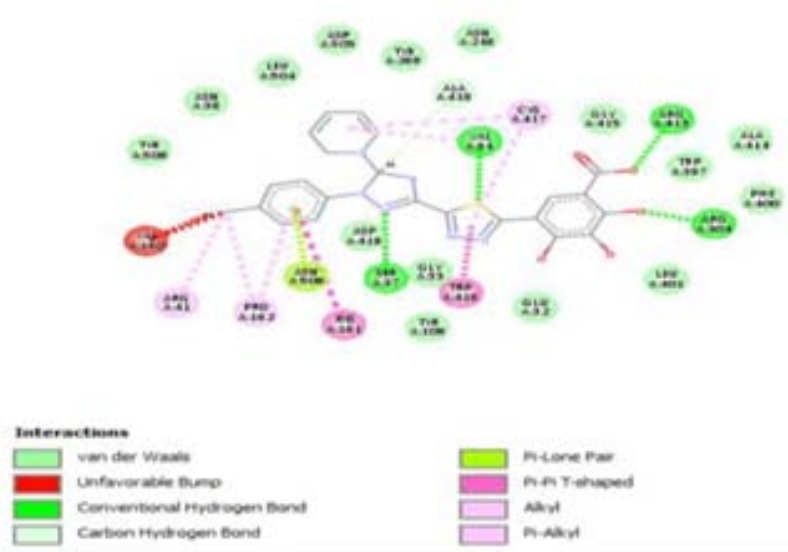

Figure 15: E-1 1B05 Receptor- Ligand 2D diagram.

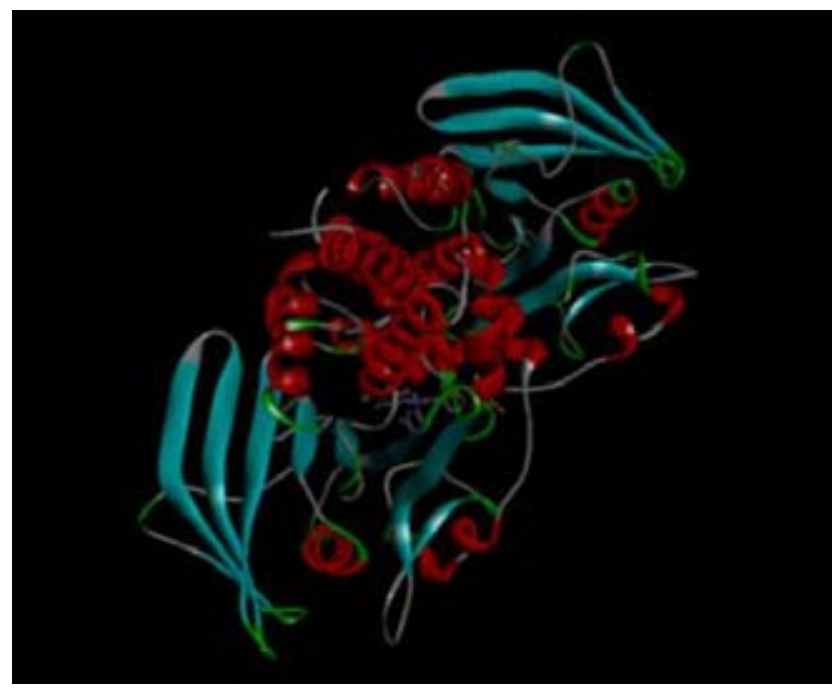

Figure 13A: E-1 1Q6S Receptor-Ligand Interaction.

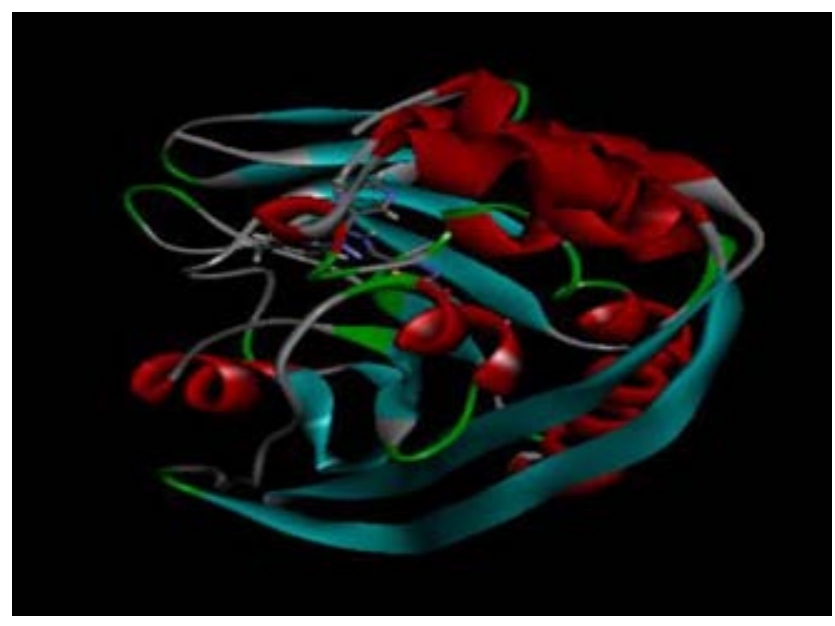

Figure 14A: E-1 1P91 Receptor-Ligand Interaction.

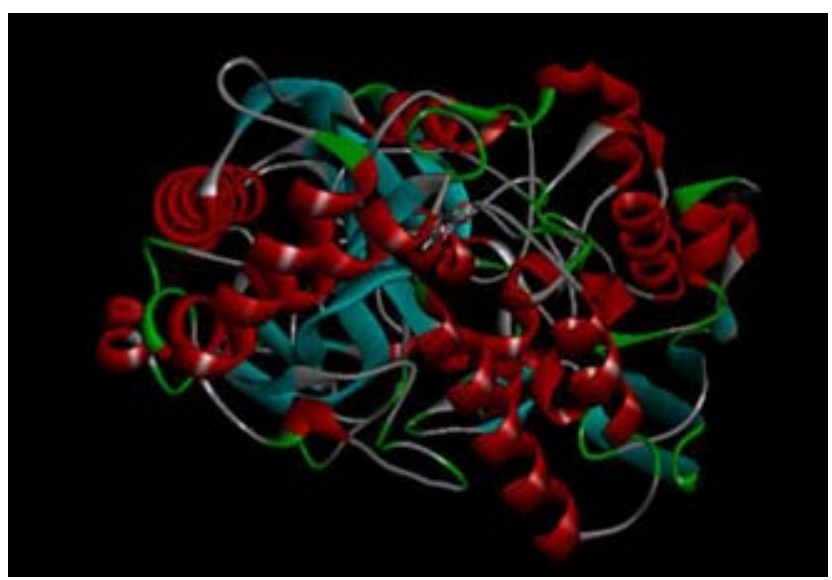

Figure 15A: E-1 1B05 Receptor-Ligand Interaction. 


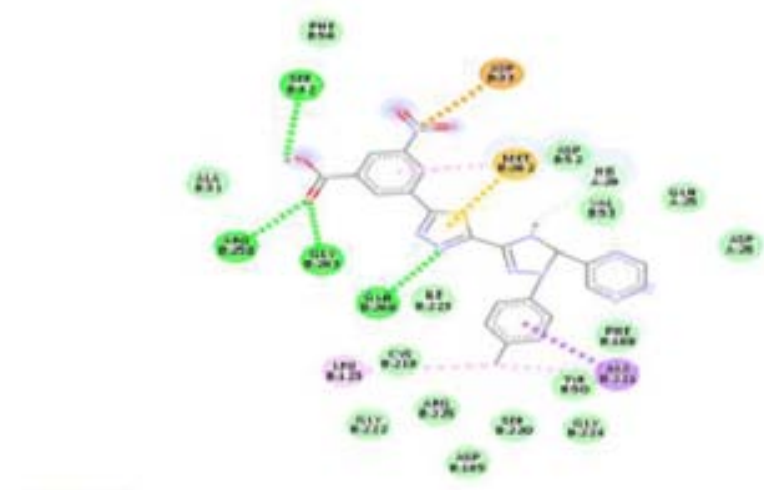

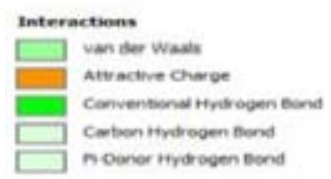

Figure 16: F-1 1Q6S Receptor- Ligand 2D diagram.
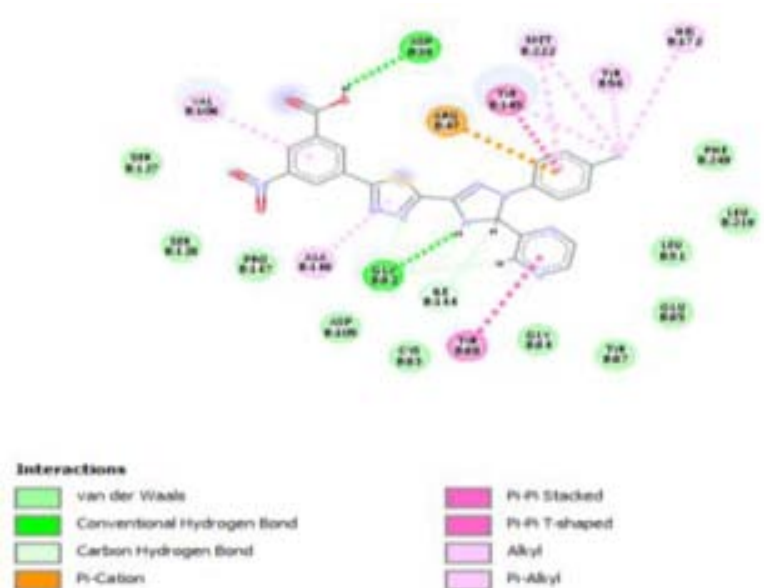

Figure 17: F-1 1P91 Receptor- Ligand 2D diagram.
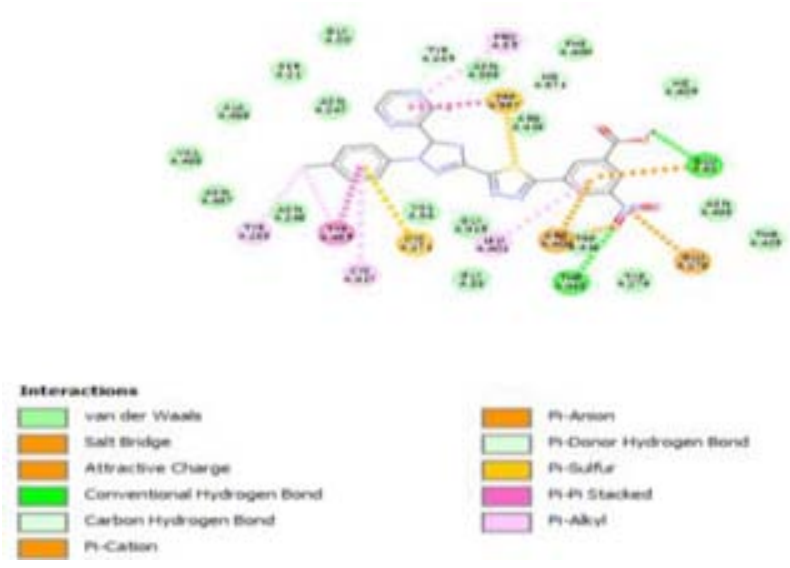

Figure 18: F-1 1B05 Receptor- Ligand 2D diagram.

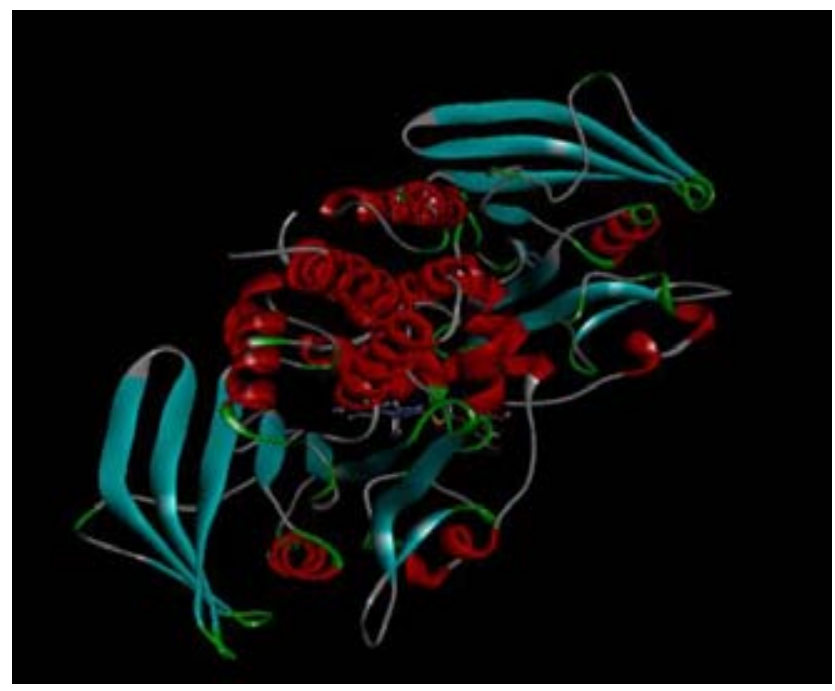

Figure 16A: F-1 1Q6S Receptor-Ligand Interaction.

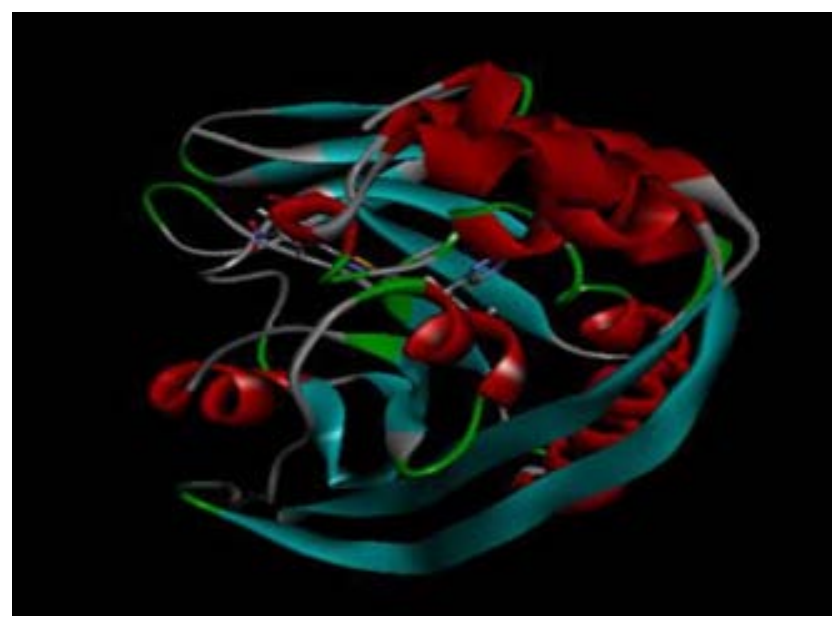

Figure 17A: F-1 1P91 Receptor-Ligand Interaction.

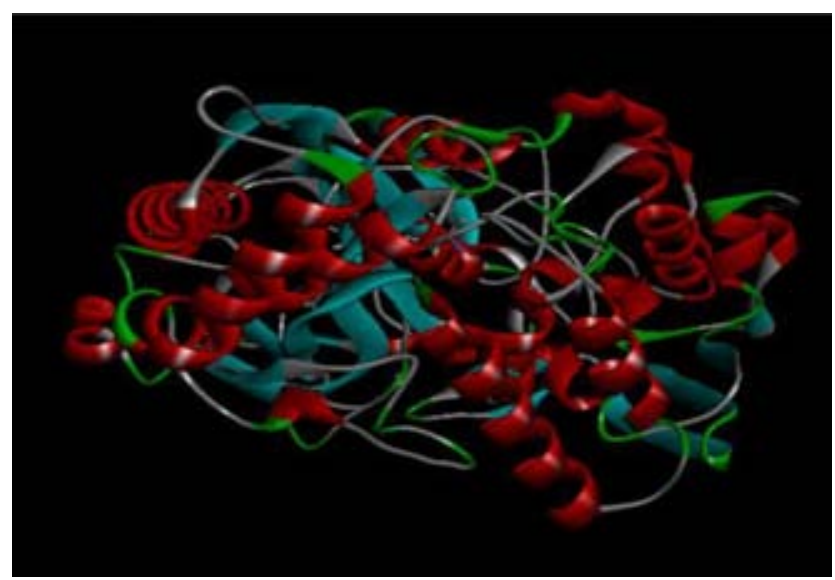

Figure 18A: F-1 1B05 Receptor-Ligand Interaction. 


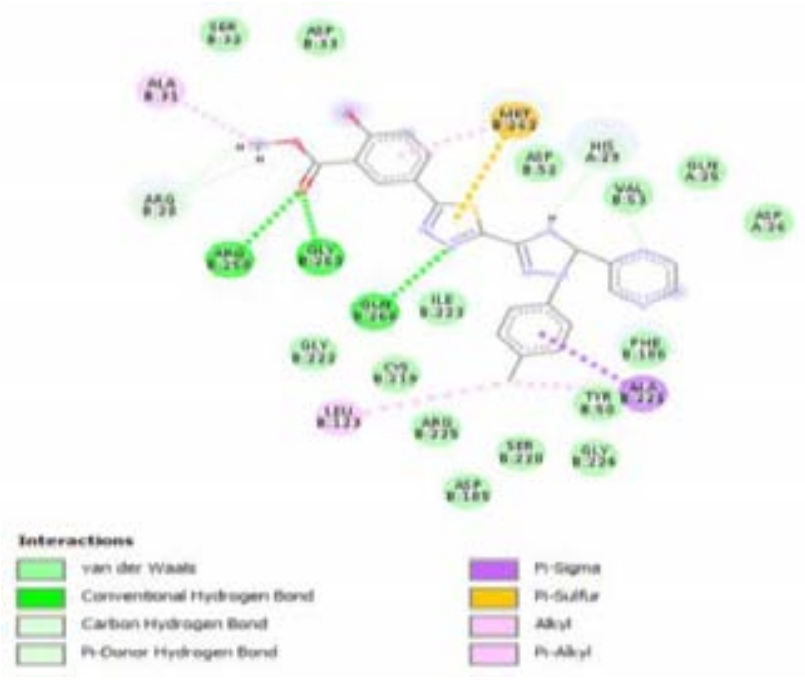

Figure 19: G-1 1Q6S Receptor- Ligand 2D diagram.

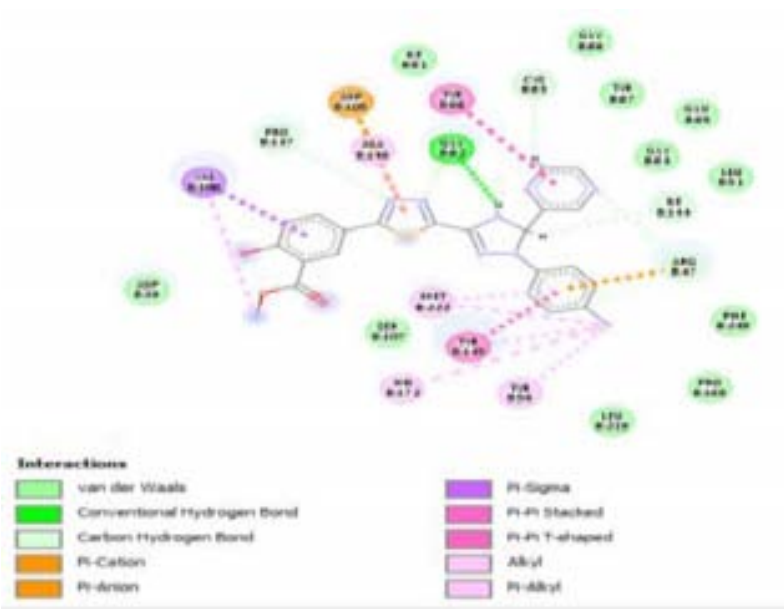

Figure 20: G-1 1P91 Receptor- Ligand 2D diagram.

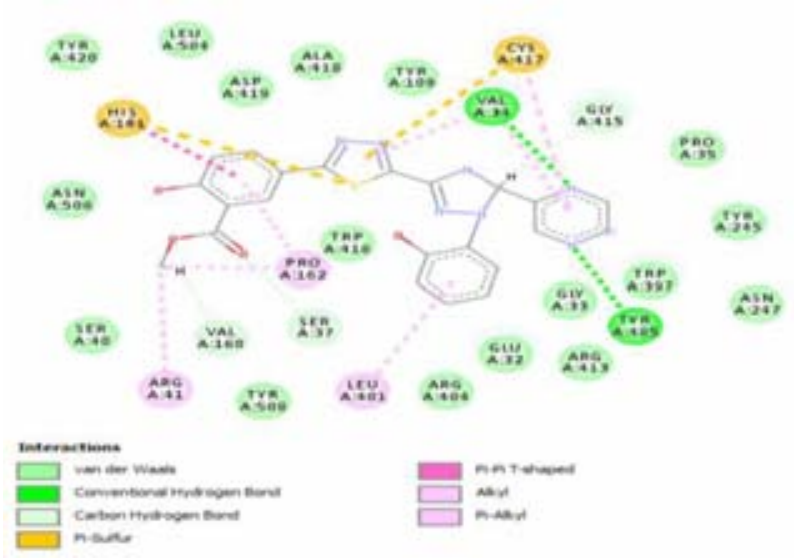

Figure 21: G-1 1B05 Receptor- Ligand 2D diagram.

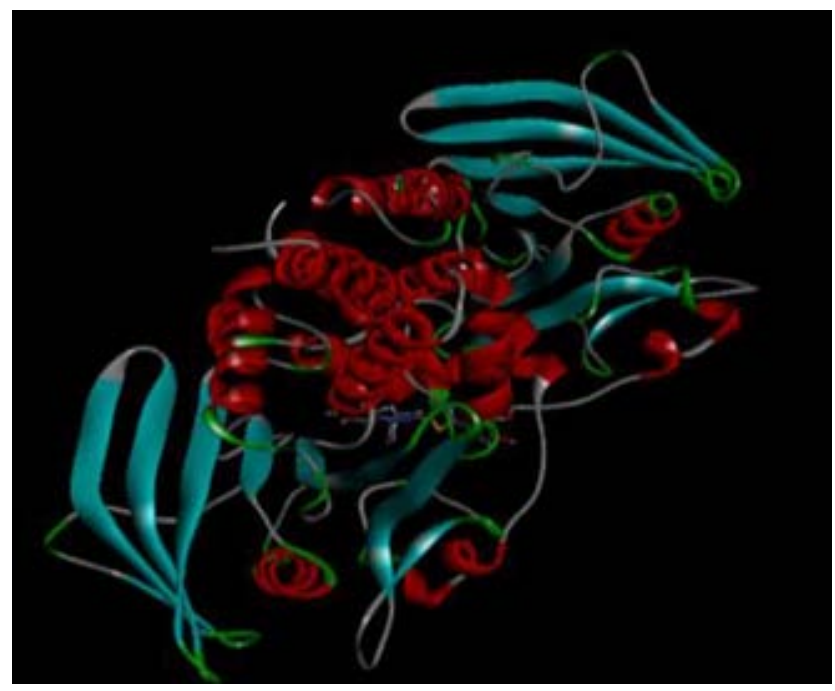

Figure 19A: G-1 1Q6S Receptor-Ligand Interaction.

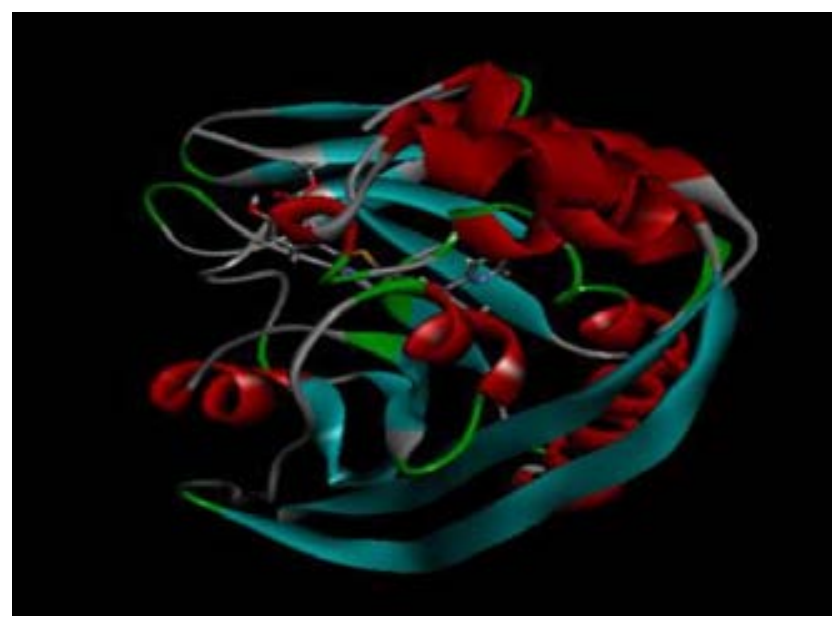

Figure 20A: G-1 1P91 Receptor-Ligand Interaction.

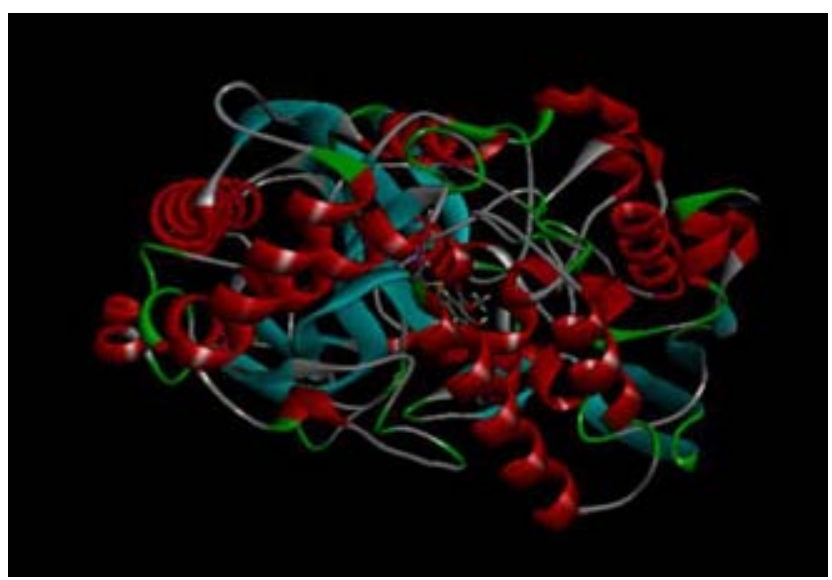

Figure 21A: G-1 1B05 Receptor-Ligand Interaction. 


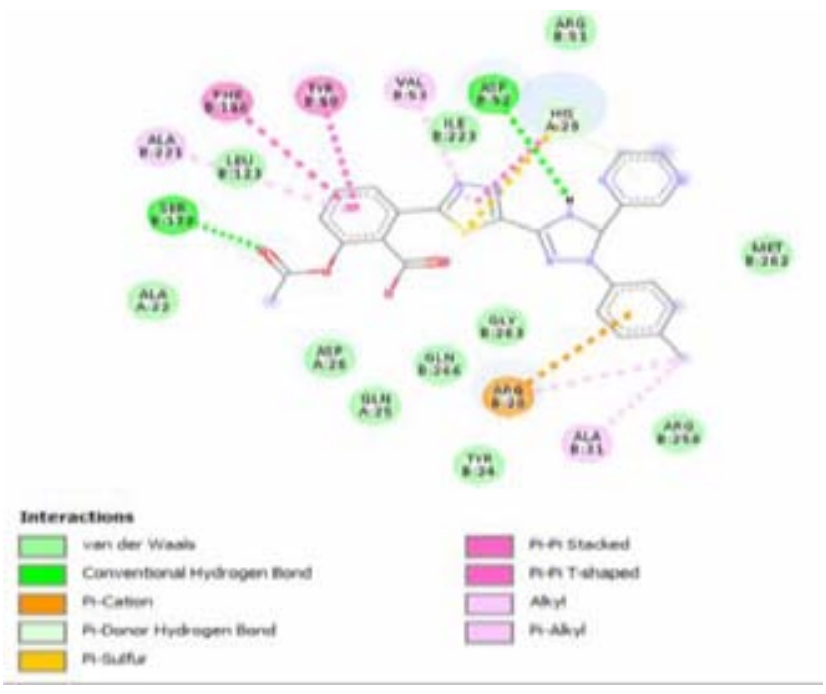

Figure 22: H-1 1Q6S Receptor- Ligand 2D diagram.
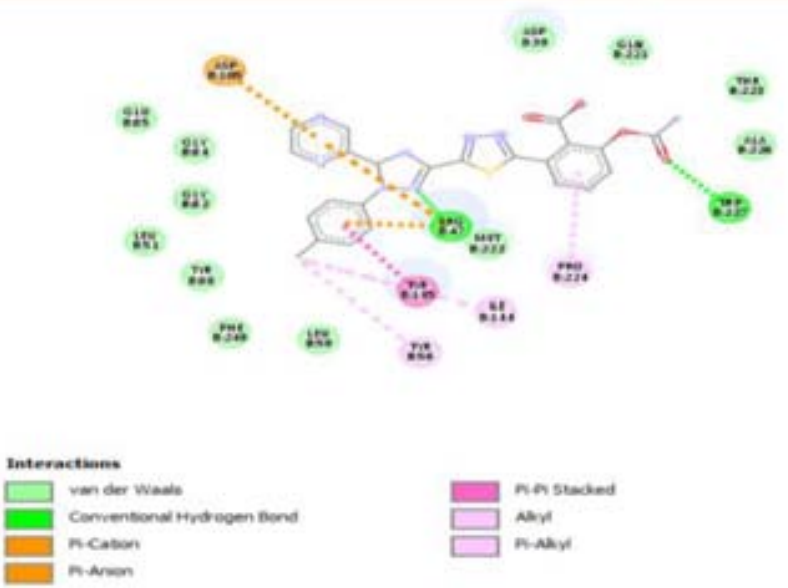

Figure 23: H-1 1P91 Receptor- Ligand 2D diagram.

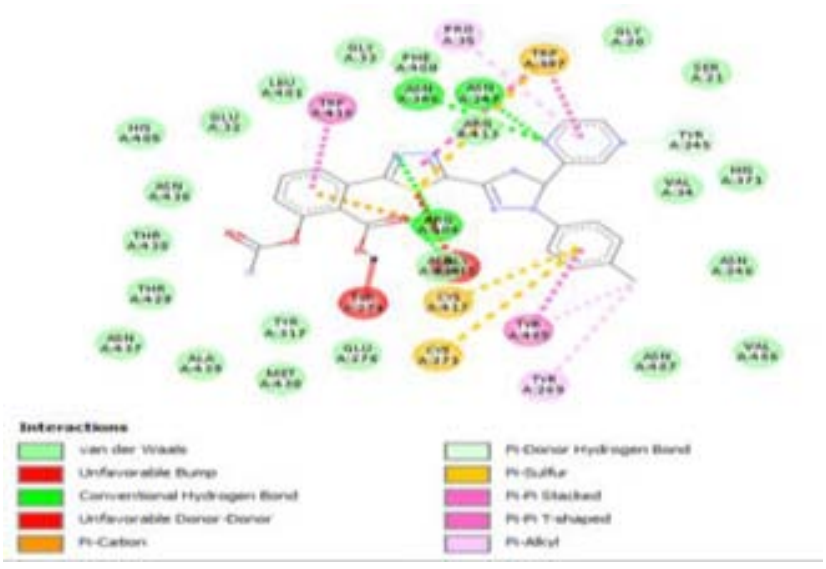

Figure 24: H-1 1B05 Receptor- Ligand 2D diagram.

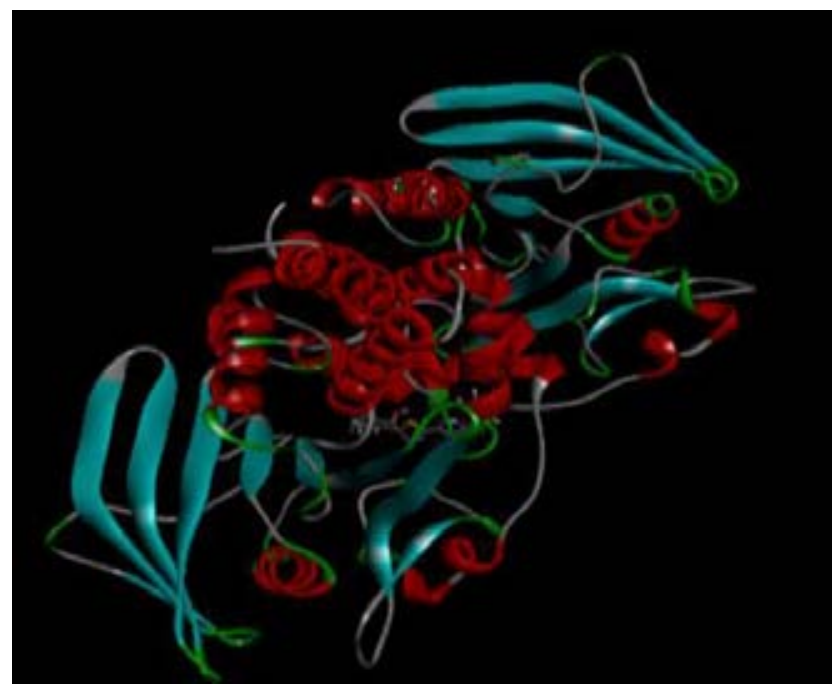

Figure 22A: H-1 1Q6S Receptor-Ligand Interaction.

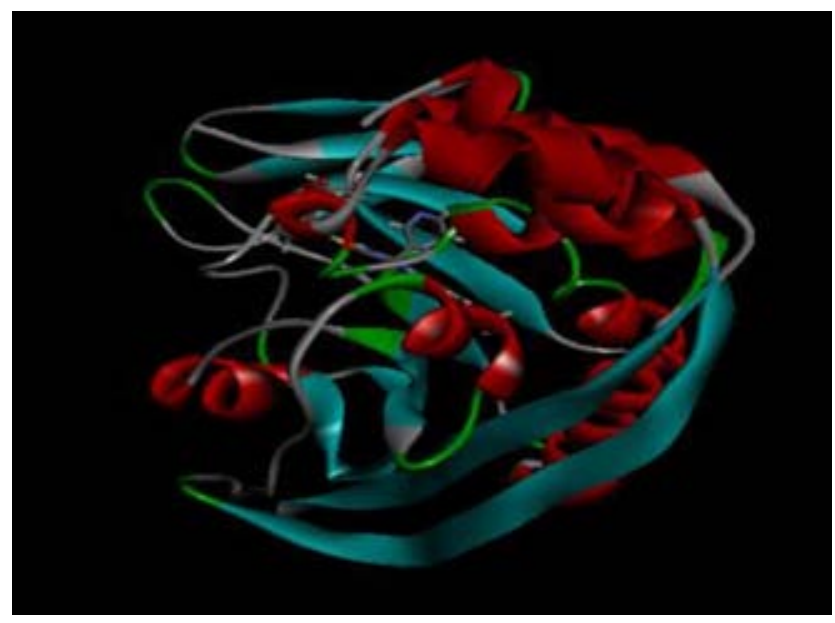

Figure 23A: H-1 1P91 Receptor-Ligand Interaction.

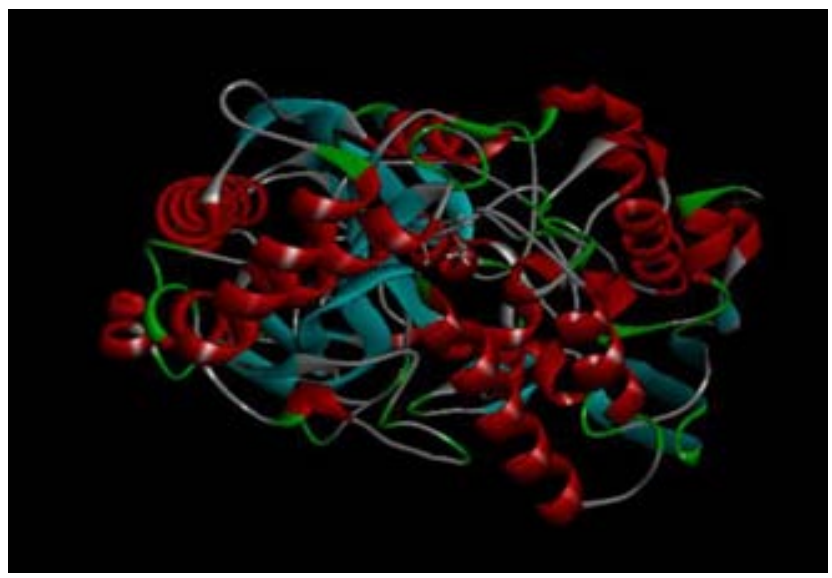

Figure 24A: H-1 1B05 Receptor-Ligand Interaction. 


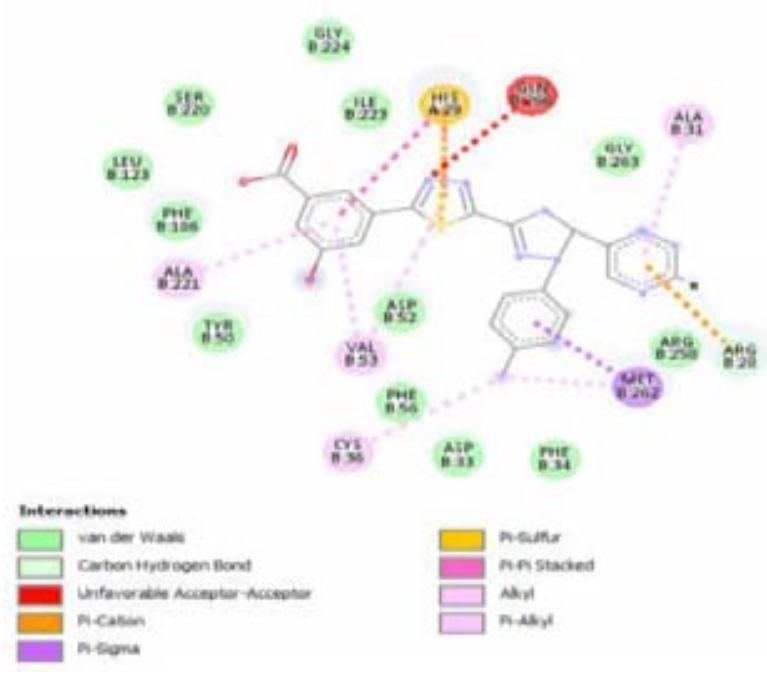

Figure 25: I-1 1Q6S Receptor- Ligand 2D diagram.

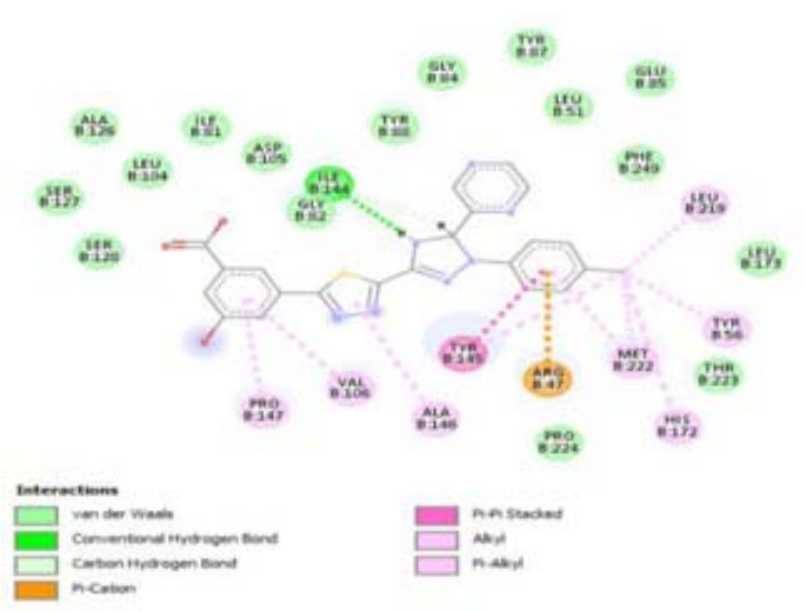

Figure 26: I-1 1P91 Receptor- Ligand 2D diagram.
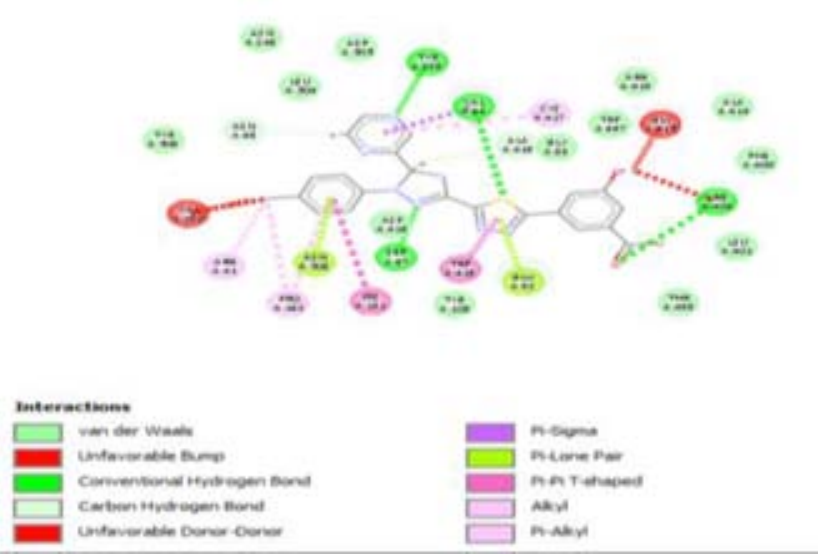

Figure 27: I-1 1B05 Receptor- Ligand 2D diagram.

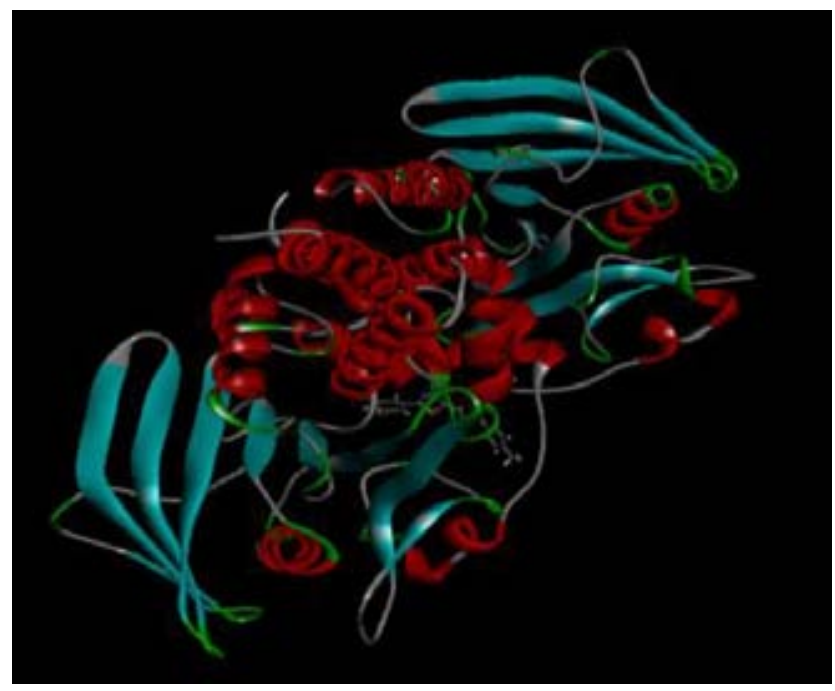

Figure 25A: I-1 1Q6S Receptor-Ligand Interaction.

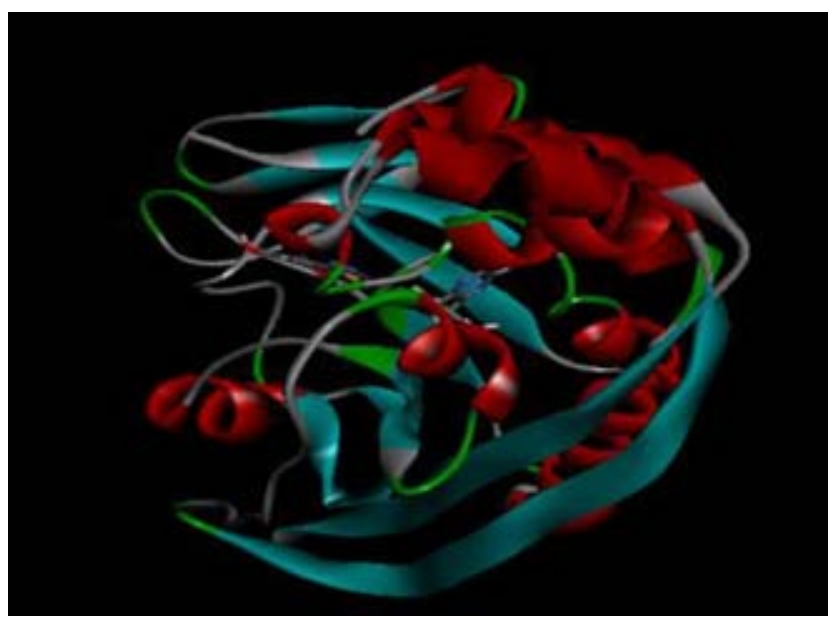

Figure 26A: I-1 1P91 Receptor-Ligand Interaction.

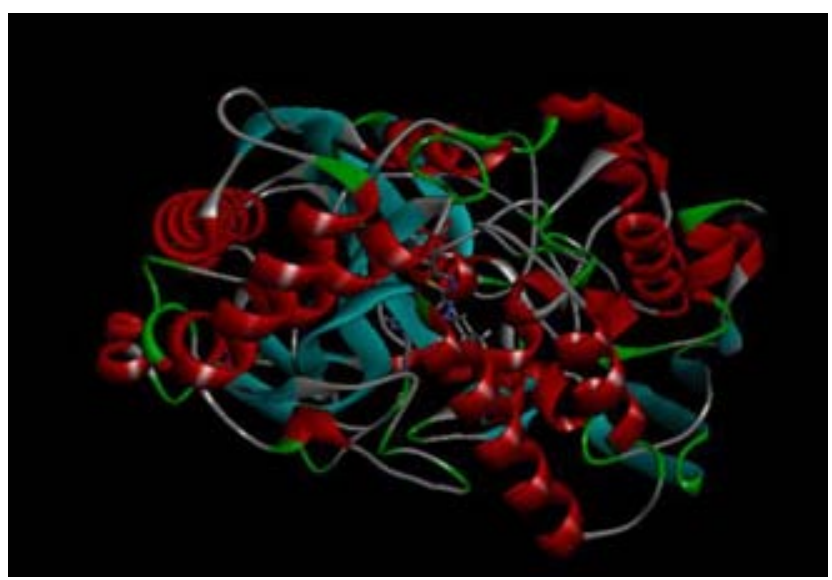

Figure 27A: I-1 1B05 Receptor-Ligand Interaction. 


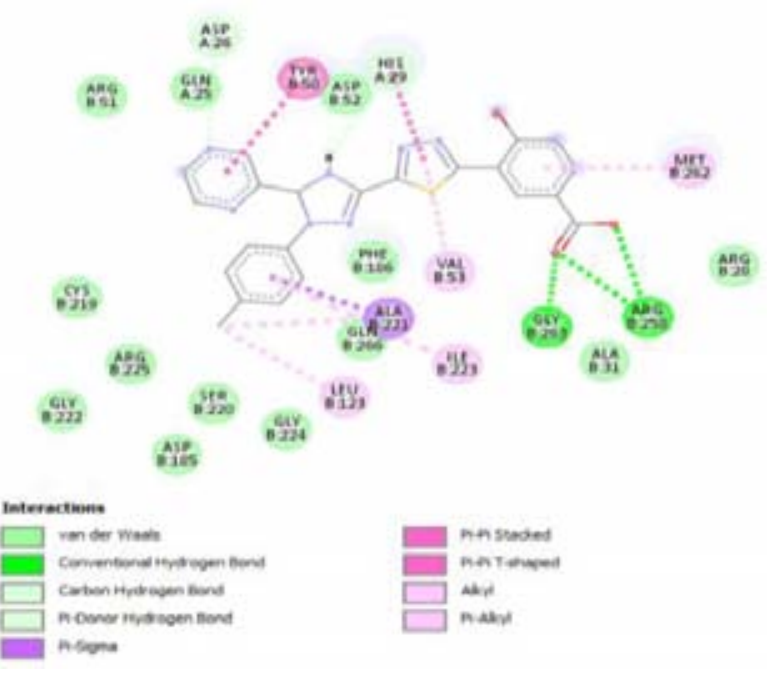

Figure 28: J-1 1Q6S Receptor- Ligand 2D diagram.

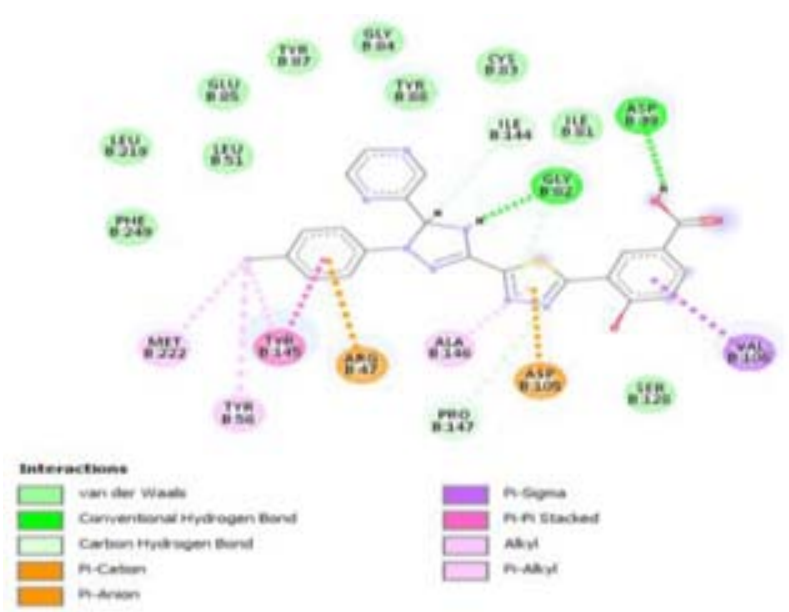

Figure 29: J-1 1P91 Receptor- Ligand 2D diagram.

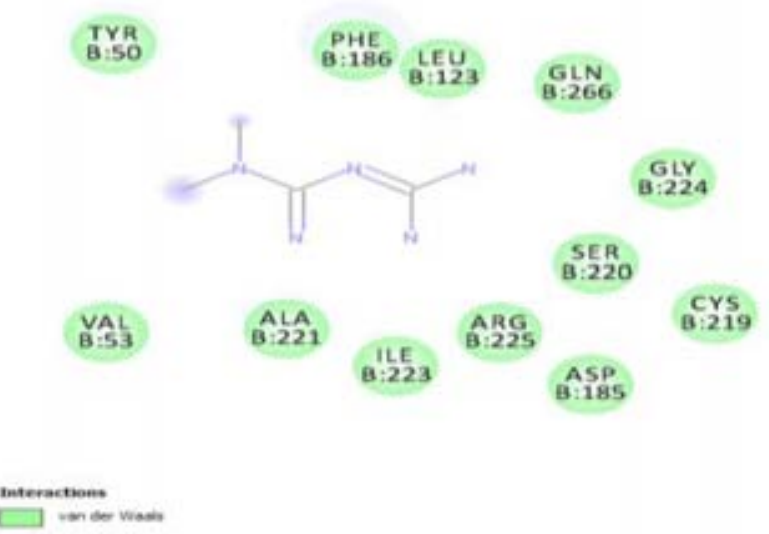

Figure 30: J-1 1B05 Receptor- Ligand 2D diagram.

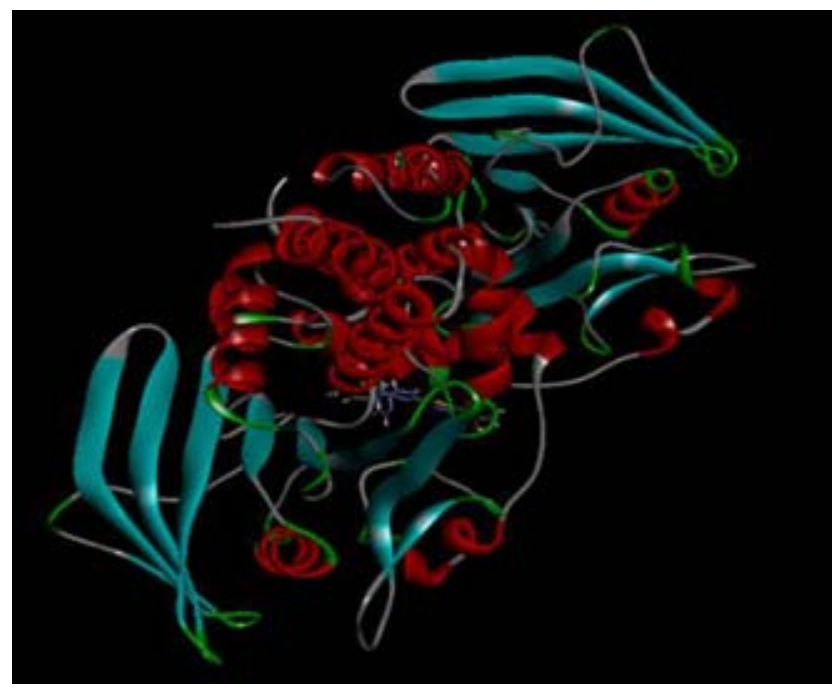

Figure 28A: J-1 1Q6S Receptor-Ligand Interaction.

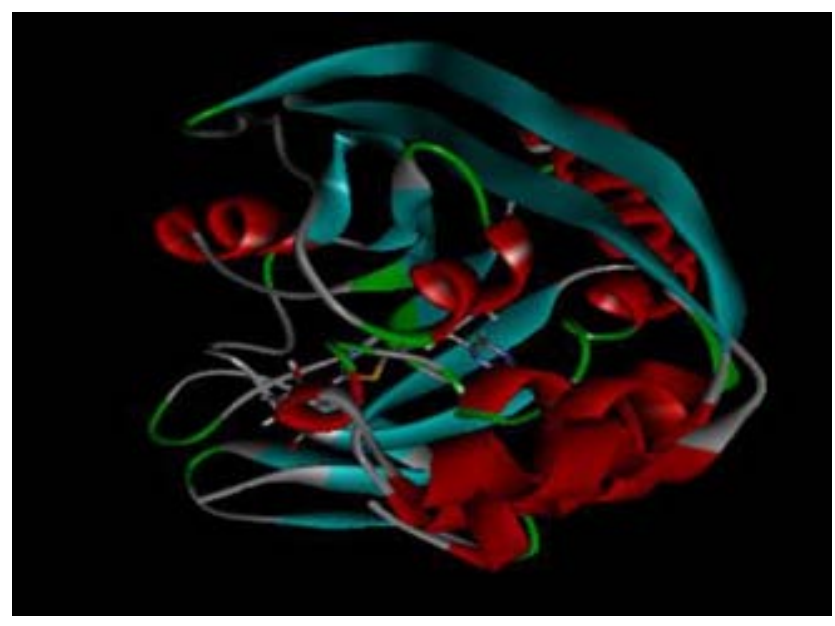

Figure 29A: J-1 1P91 Receptor-Ligand Interaction.

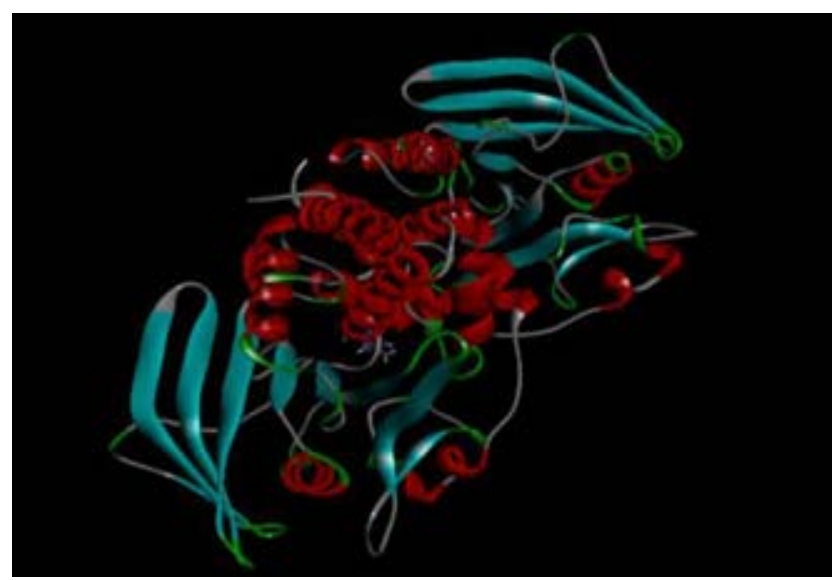

Figure 30A: J-1 1B05 Receptor-Ligand Interaction. 


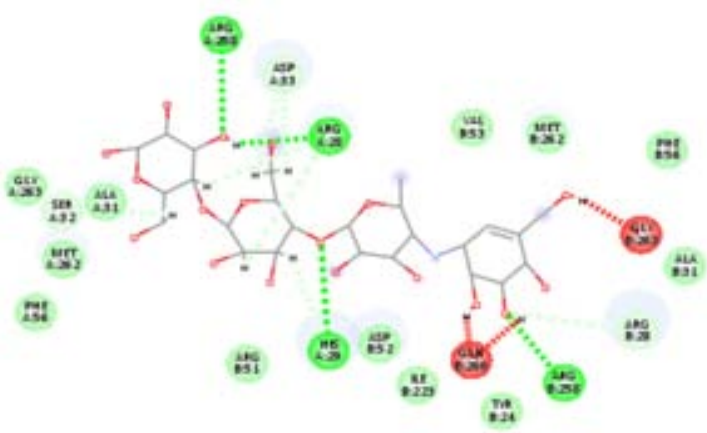

Interactions

$\square$ van der Wask
Comventonal Herdrogen Bond

Figure 31: K-1 1Q6S Receptor- Ligand 2D diagram.

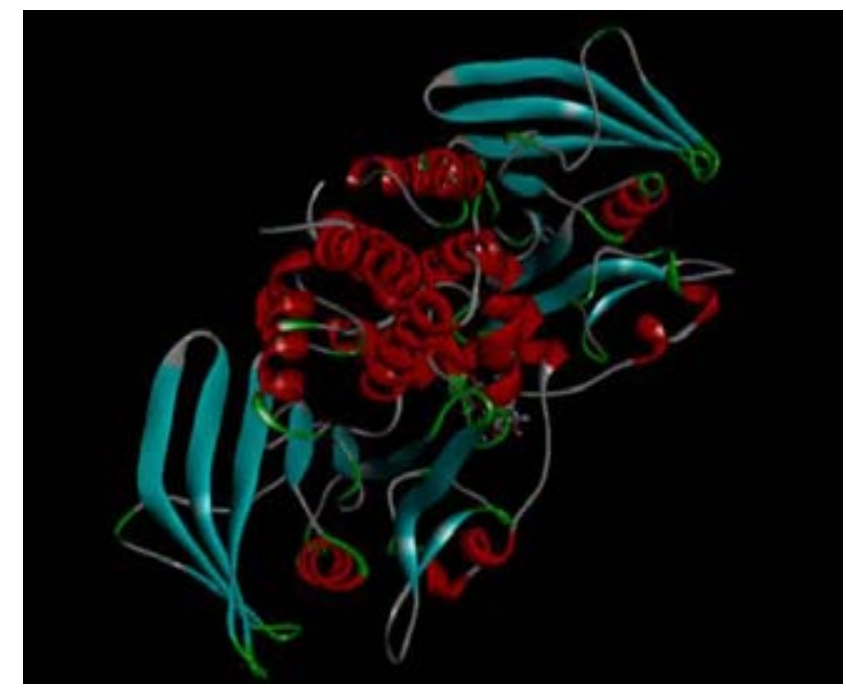

Figure 31A: K-1 1Q6S Receptor-Ligand Interaction.

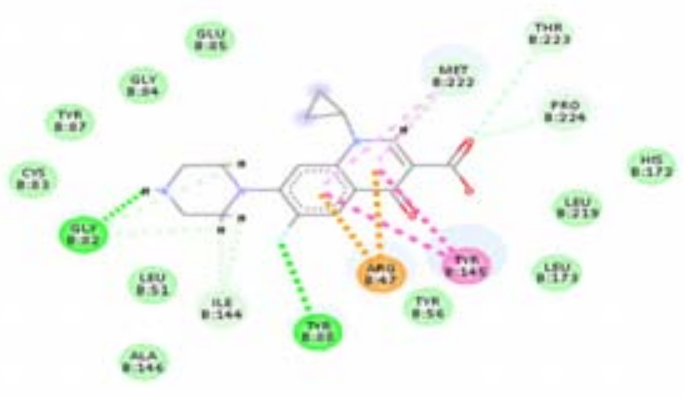
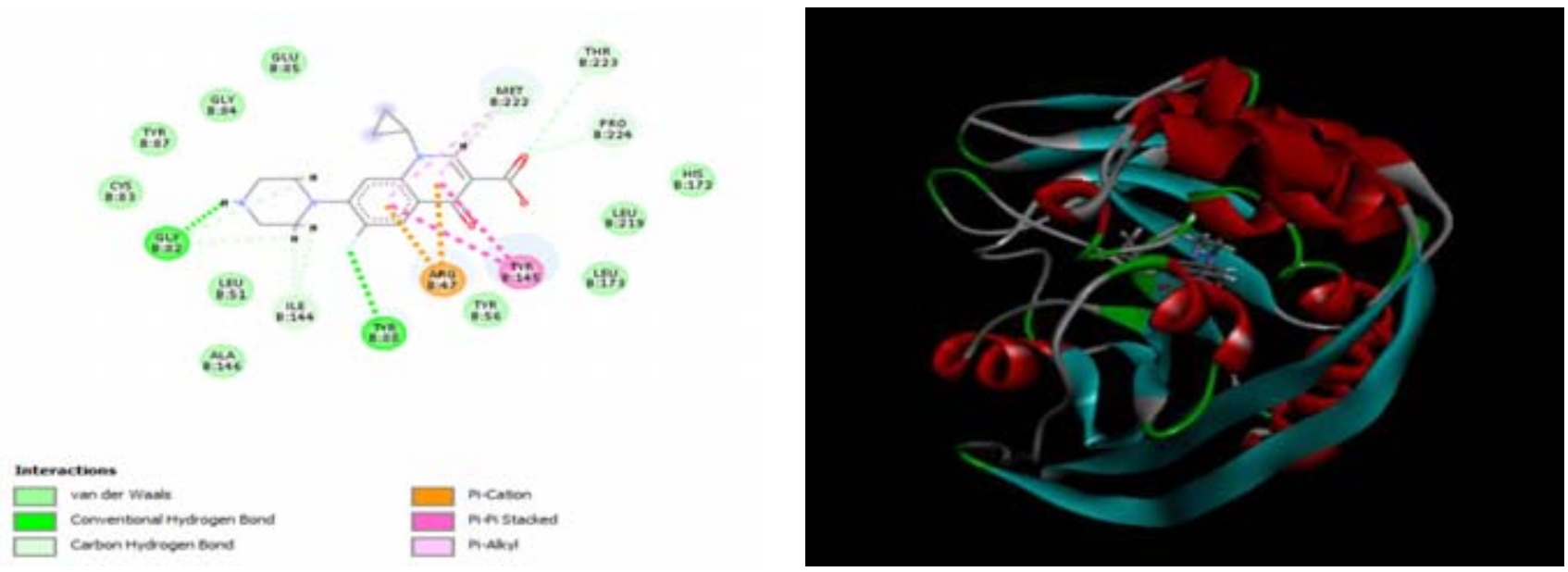

Figure 32A: K-1 1P91 Receptor-Ligand Interaction.
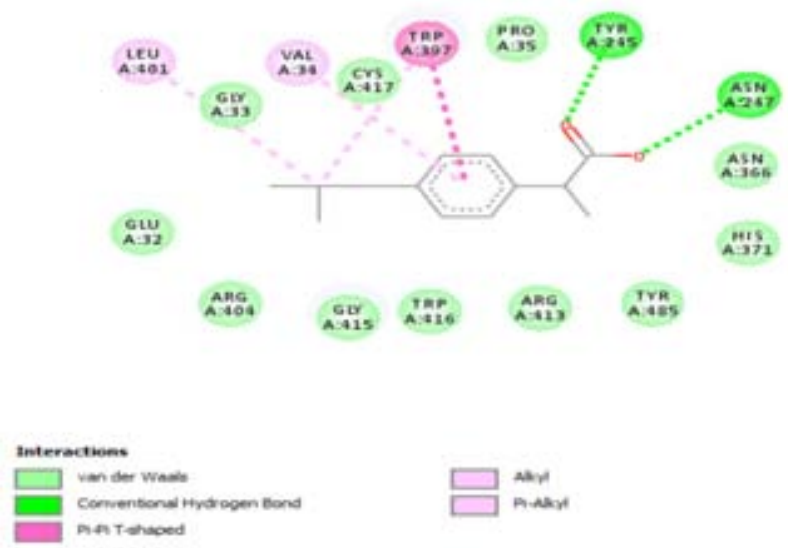

Figure 33: K-1 1B05 Receptor- Ligand 2D diagram.

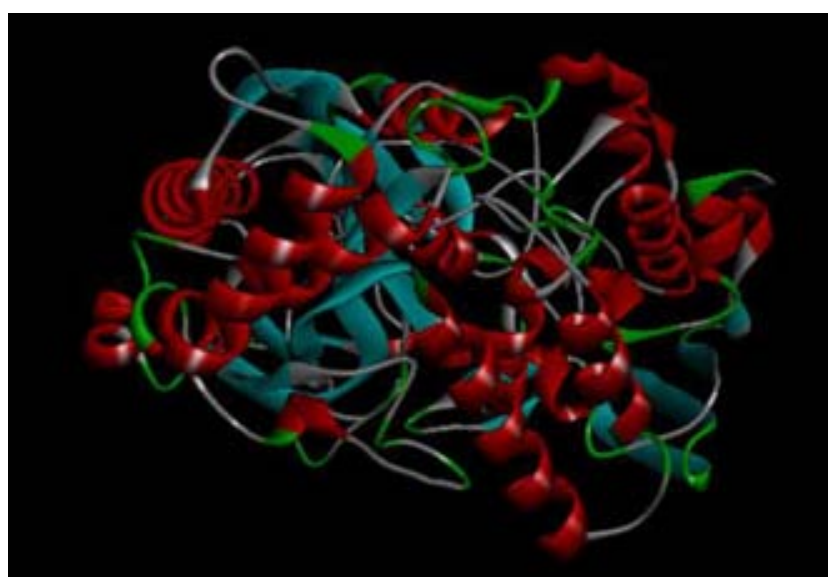

Figure 33A: K-1 1B05 Receptor-Ligand Interaction. 
anti-inflammatory activity. With appropriate modification these compounds can be better explored for their antidiabetic activities in the future. Promising antidiabetic activities of these compounds are taken into account for drug development and drug discovery Toxicological studies of these compounds will be carried out in the future and effective therapeutic index. In view of the above facts it was felt that some were interested in triazo-synthesis. The docking score is less negative than Triazolo-thiadiazole derivatives, so the docking score of Triazolo-thiadiazole derivatives appears to be better.

\section{ACKNOWLEDGEMENT}

My special thanks to the Pravara Rural College of Pharmacy, Pravarnagar and Department of pharmacy, Sumandeep Vidyapeeth Deemed to be University, for providing the infrastructure and facilities for this research work. I am also grateful to my loving parents and all family members who have been the driving force behind progress and success in every step of my life.

\section{CONFLICT OF INTEREST}

The authors declare no competing interest.

\section{ABBREVIATIONS}

M.F: Molecular formula; M.W: Molecular weight; logP: logarithm of compound partition; HBD: number of hydrogen bond donor; HBA: number of hydrogen bond acceptors; NROTB: number of rotatable bonds.

\section{REFERENCES}

1. Winter CA, Risley EA, Nuss GN. Carrageenan-induced edema in the hind paw of mice as an assay for anti-inflammatory drugs. Proscock Exp Biol. 1962;86(111):544-47.

2. Vivona N, Busemi S, Esta S. CaronaTPhotoinduced molecular rearrangement. Photochemistry of 1,2,4-oxadizoles in the presence of sulfur nucleophiles. Synthesis of 1,2,4-thiadizole. Tetrahedron. 1997;53(12):629.

3. Cho NS, Shon HI, Párkányi C. Synthesis of 5-(aroylamino)-2-methyl-2 $\mathrm{H},-1,2,4$-thiadiazol-3-ones by oxidative cyclization of 1-aroyl-5-methyl-2thiobiurets. Journal of Heterocyclic Chemistry. 1991;28(7):1645-9. doi: 10.1002/jhet.5570280701.

4. Mamaeva EA, Bakibaev AA. Oxidative azacyclization of 1-monosubstituted thioureas in reaction with [bis(acyloxy)iodo]arenes to form 1,2,4-thiadiazole derivatives. Tetrahedron. 2003;59(38):7521-5. doi: 10.1016/S00404020(03)01176-1.

5. Turner S, Mayer M. Antihypertensive thiadiazole. 1. Synth Some. 1988; 31;902:2-aryl-5-hydrazino-1,3,4-thiadizoles with vasodilator activity, J of Med Che..

6. El Shehry MF, Abu-Hashem AA, El-Telbani EM. Synthesis of 3-((2,4-dichlorophenoxy)methyl)-1,2,4-triazolo(thiadiazoles and thiadiazines) as anti-inflammatory and molluscicidal agents. Eur J Med Chem. 2010;45(5):1906-11. doi: 10.1016/j.ejmech.2010.01.030.

7. Elias G, Rao MNA. Inhibition of albumin denaturation and antiinflammatory activity of dehydrozingerone and its analogs. Indian $J$ Exp Biol. 1988;26(7):540-2. PMID 3198157.

8. Leeson PD, Springthorpe B. The influence of drug-like concepts on decisionmaking in medicinal chemistry. Nat Rev Drug Discov. 2007;6(11):881-90. doi: 10.1038/nrd2445, PMID 17971784.

9. Lipinski CA, Lombardo F, Dominy BW, Feeney PJ. Experimental and computational approaches to estimate solubility and permeability in drug discovery and development settings. Adv Drug Deliv Rev. 2001;46(1-3):3-26. doi: 10.1016/s0169-409x(00)00129-0. PMID 11259830.

10. Mohan H. Textbook of pathology Jaypee Brothers Medical publishers limited; 2000. p. 114-60.

11. Furniss BS, Hanford AJ, Smith PWJ, Pathel AR. Vogel's text book of practical organic chemistry. Vol. 2007(5). ELBS Publications Private Limited; 1260. p. 229.

12. Alagarasamy V. Textbook of medicinal chemistry. Volume I, Elsevier Publications; 2010. p. 204-6.

\section{SUMMARY}

The discovery of new effective antimycobacterium, anti-inflammatory, anti-diabetic and antimicrobial agents are imperative. Swiss programs to predict Triazolo-thiadiazole derivatives properties that are important for drug profile. Later, all of them were docked into the active sites of enzymes namely Ribosomal RNA large subunit methyltransferase (1P91), Periplasmic Oligopeptide-Binding Protein (1B05) and Protein-tyrosine phosphatase, non-receptor type 1 (1q6s), those were considered in Antidiabetic studies of triazolo-thiadiazole derivative. Docking study when compared with Triazolo-thiadiazole derivatives with standard drug, derivative docking result is better. Ciprofloxacin, ibuprofen, and acarbose have been used as standard drugs for antimicrobial, anti-inflammatory and anti-diabetic activity in comparative docking studies. 
PICTORIAL ABSTRACT

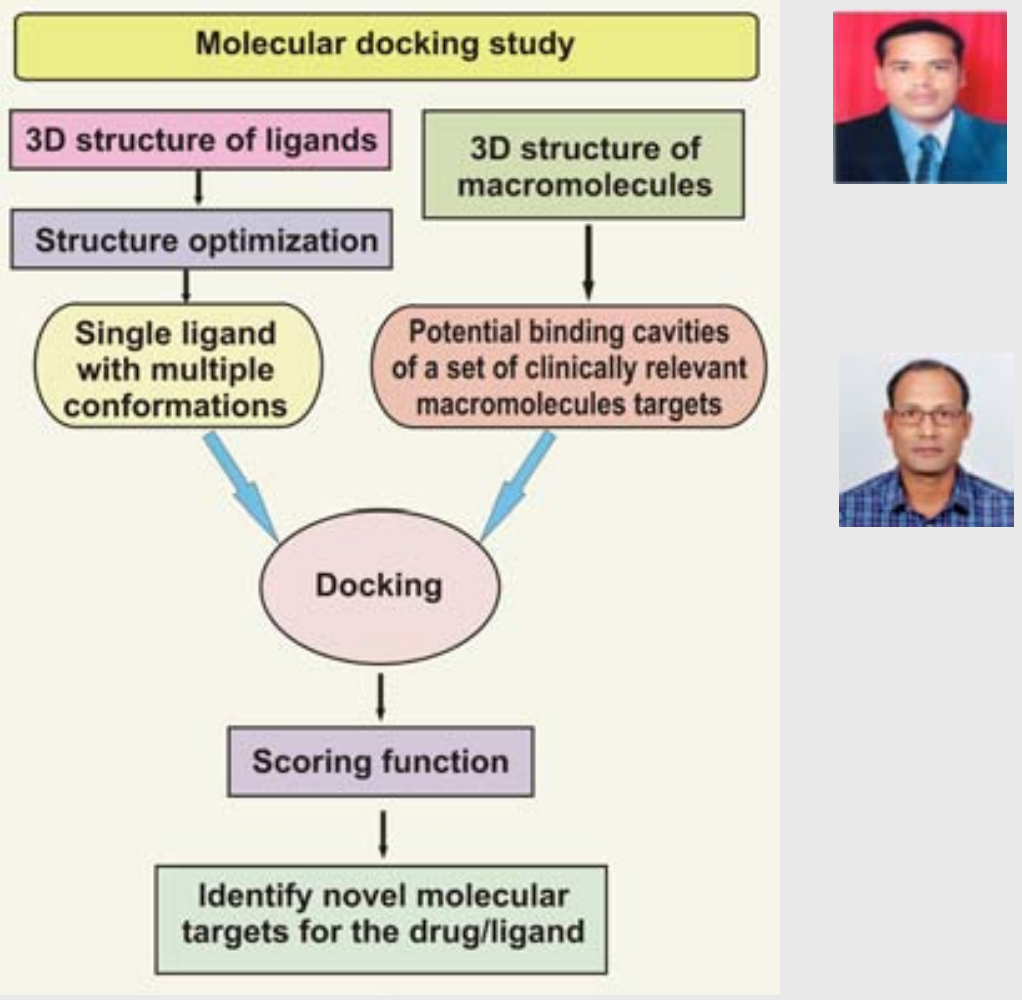

\section{About Authors}

Mr. Amol Sopanrao Dighe Ph.D. Scholar, Department of Pharmacy, Sumandeep Vidyapeeth Deemed to be University, Pipariya, Vadodara, Gujarat State, India Assistant Professor, Department of Pharmaceutical Chemistry, Pravara Rural College of Pharmacy, Loni (413736), $\mathrm{MH}$, India.

Dr. Ashim Kumar, Professor, Department of Pharmacy, Sumandeep Vidyapeeth Deemed to be University, Vadodara-391760, Gujarat, India.

Cite this article: Dighe AS, Sen AK. In silico Investigation and Molecular Docking Study of Triazolo-thiadiazole Derivatives for Antimicrobial, Anti-inflammatory and Anti-diabetic Activity. Indian J of Pharmaceutical Education and Research. 2021;55(4):1125-44. 